\title{
Impact of inactivity and exercise on the vasculature in humans
}

\author{
Dick H. J. Thijssen • Andrew J. Maiorana • Gerry O'Driscoll • \\ Nigel T. Cable $\cdot$ Maria T. E. Hopman • Daniel J. Green
}

Accepted: 17 October 2009/Published online: 27 November 2009

(C) The Author(s) 2009. This article is published with open access at Springerlink.com

\begin{abstract}
The effects of inactivity and exercise training on established and novel cardiovascular risk factors are relatively modest and do not account for the impact of inactivity and exercise on vascular risk. We examine evidence that inactivity and exercise have direct effects on both vasculature function and structure in humans. Physical deconditioning is associated with enhanced
\end{abstract}

Communicated by Susan Ward.

D. H. J. Thijssen · N. T. Cable · D. J. Green ( ()

Research Institute for Sport and Exercise Sciences, Liverpool John Moores University, Henry Cotton Campus, 15-21 Webster Street, Liverpool L3 2ET, UK

e-mail:d.j.green@ljmu.ac.uk

D. H. J. Thijssen

e-mail: d.thijssen@fysiol.umcn.nl

D. H. J. Thijssen · M. T. E. Hopman

Department of Physiology, Radboud University Nijmegen

Medical Centre, Nijmegen, The Netherlands

\section{A. J. Maiorana · G. O’Driscoll}

Advanced Heart Failure and Cardiac Transplant Service, Royal Perth Hospital, Perth, Australia

\section{A. J. Maiorana}

School of Physiotherapy, Curtin University of Technology, Perth, Australia

\section{G. O'Driscoll}

School of Medicine, University of Notre Dame, Fremantle, Australia

D. J. Green

School of Sport Science, Exercise and Health,

The University of Western Australia, Perth, Australia vasoconstrictor tone and has profound and rapid effects on arterial remodelling in both large and smaller arteries. Evidence for an effect of deconditioning on vasodilator function is less consistent. Studies of the impact of exercise training suggest that both functional and structural remodelling adaptations occur and that the magnitude and time-course of these changes depends upon training duration and intensity and the vessel beds involved. Inactivity and exercise have direct "vascular deconditioning and conditioning" effects which likely modify cardiovascular risk.

Keywords Physical inactivity - Exercise training . Endothelium · Vascular adaptations · Nitric oxide

\section{Introduction}

Physical activity, inactivity and cardiovascular risk

Contemporary westerners have reached an historical pinnacle of physical inactivity and further technological change is likely to reinforce this (Booth et al. 2002). Physical inactivity is an independent risk factor for atherosclerosis, cardiovascular diseases and diabetes (Blair et al. 1995; LaMonte et al. 2005; Manson et al. 1999) and low cardiopulmonary fitness is a strong independent predictor of all-cause mortality (Wei et al. 1999). Sedentary living is estimated to be responsible for approximately onethird of deaths due to coronary heart disease, colon cancer, and type 2 diabetes (Powell and Blair 1994). Physical inactivity is therefore a key factor in the etiology and progression of chronic diseases, including cardiovascular and metabolic diseases which are common, debilitating and costly. Given the low daily energy expenditure which is 
characteristic of modern living (Booth et al. 2002), the consequences of physical inactivity seem likely to worsen.

Regular physical exercise is associated with reduction in primary (Hakim et al. 1999; Myers et al. 2002; Paffenbarger et al. 1986; Sesso et al. 2000) and secondary vascular events (Jolliffe et al. 2001; Oldridge et al. 1988). Meta-analyses, including those of exercise-based cardiac rehabilitation undertaken in the contemporary statin, ACE inhibitor and revascularisation era, indicate that a $\sim 30 \%$ exercise-related benefit is evident in terms of cardiac events, relative to usual care (Green et al. 2008c). Indeed, some expert opinion suggests that the most physically active individuals demonstrate CAD rates half those of the most sedentary (Thompson et al. 2003). This magnitude of benefit approximates or exceeds that associated with antihypertensive or lipid lowering interventions in large multicenter trials (Turnbull 2003; Wilt et al. 2004). It is well established that individuals with higher cardiopulmonary fitness exhibit lower cardiovascular disease rates than unfit individuals (Thompson et al. 2003), with the relative risk of being unfit exceeding that associated with smoking, elevated systolic blood pressure, hypercholesterolemia and overweight/obesity (Blair et al. 1996). These data indicate that exercise training and maintenance of physical fitness have important impacts on the prevalence and progression of cardiovascular diseases in humans.

\section{Does risk factor modulation explain the effects of inactivity and exercise on $\mathrm{CV}$ risk?}

Detrimental changes in cardiovascular risk factors have been suggested to explain the increased cardiovascular risk associated with chronic inactivity (Garshick et al. 2005; Groah et al. 2001; Imai et al. 2004). Human models of short-term physical inactivity (4-8 weeks) demonstrate no change in blood pressure, obesity, BMI or cholesterol levels (Bleeker et al. 2005a, b, c; Demiot et al. 2007; Pawelczyk et al. 2001; Thijssen et al. 2007b). Subjects with a spinal cord injury (SCI), who are predisposed to develop cardiovascular diseases (Garshick et al. 2005; Groah et al. 2001; Imai et al. 2004), have similar cholesterol, triglyceride and blood pressure levels to healthy subjects (Bauman et al. 1992; Cardus et al. 1992; Krum et al. 1992; Liang et al. 2007). Recently, prevalence rates of the metabolic syndrome and traditional cardiovascular risk factors were compared between 185 SCI subjects and age-, gender- and race-matched controls. No differences were found for traditional risk factors between both groups and SCI patients demonstrated lower levels of blood cholesterol and glucose (Liang et al. 2007). These results suggest that the strong link between physical inactivity and cardiovascular mortality and morbidity cannot be fully explained by an effect of inactivity on traditional cardiovascular risk factors.

The effects of exercise on conventional risk factors are substantially less than those achieved by pharmacological therapies and also much less than that required to explain the mortality benefits associated with exercise and fitness (Green et al. 2008c). For example, the magnitude of decrease in LDL required to explain a $30 \%$ mortality benefit, approximates $25 \%$ (LIPID study group 1998). The impact of exercise training on LDL is typically $<5 \%$ (Thompson et al. 2003). In addition, improvement in traditional risk factors cannot solely account for the magnitude of risk reduction associated with exercise training, since the association with reduced mortality is independent of these risk factors (Dimmeler and Zeiher 2003; Shephard and Balady 1999). Indeed, a recent analysis of 27,000 subjects in the Women's Health Study reported that differences in risk factors explained $59 \%$ of the relative cardiovascular risk reduction associated with exercise (Mora et al. 2007). The impact of hemoglobin A1c, lipid sub profiles, lipoprotein (a), apolipoprotein A1, apolipoprotein B-100, creatinine, homocysteine, hs-CRP, fibrinogen, s-ICAM-1, weight, height, BP and diabetes were taken into account. This statistical modelling suggests that at least $40 \%$ of the risk reduction associated with exercise cannot be explained by establish risk factors (Fig. 1). The



Fig. 1 Percentage reduction in CVD events associated with physical activity that is explained by risk factors (adapted from Mora et al. 2007). Differences in risk factors explain $\sim 59 \%$ of the relative cardiovascular risk reduction associated with exercise. This statistical modeling suggests that at least $40 \%$ of the risk reduction associated with exercise cannot be explained by established or emerging risk factors 
mechanisms responsible for the cardiovascular benefits of exercise in humans can therefore not be solely attributed to risk factor modulation.

In summary, traditional cardiovascular risk factors do not appear to explain the link between cardiovascular risk and physical inactivity, whilst at least $40 \%$ of the cardiovascular risk reduction attributable of exercise training remains unexplained. In this review, we examine evidence supporting the notion that inactivity and exercise have direct effects on the function and structure of the vasculature and play an important role in explaining the links between inactivity, exercise and cardiovascular risk. We propose that inactivity and exercise training have direct "vascular deconditioning and conditioning" effects, which modify cardiovascular risk.

\section{Effects of physical inactivity on the vasculature in humans}

Studies of the impact of inactivity on the vasculature in humans have adopted different intervention approaches including space travel and (head-down) bed rest, unilateral lower limb immobilisation (ULLS), immobilization via casting and assessment of subjects with spinal cord injury. Each of these approaches has its limitations. For example, changes in plasma volume accompany space flight and bed rest (Convertino et al. 1998) whilst upper extremity activity is not typically unrestricted in the bed-rest model. ULLS is only suitable to study localized deconditioning in one lower limb and there is apparently an increased risk of (deep venous) thrombosis (Berg and Tesch 1996; Bleeker et al. 2004; Gamrin et al. 1998) [suggested incidence of $2.7 \%$ (Bleeker et al. 2004)]. Casting of a limb (lower leg or forearm) (Green et al. 1997) typically follows a fracture or trauma and vascular changes to "inactivity" may therefore be influenced by the impact of healing and inflammatory processes.

Finally, it has been suggested that loss of supraspinal sympathetic vascular tone of the legs may affect vascular function and structure independent of the effects of inactivity per se. However, sympathectomized patients, who lack sympathetic vascular innervation, but participate in normal physical activity, do not exhibit the structural or functional vascular adaptations typically observed in the SCI model (Eisenach et al. 2002; Hashmonai and Kopelman 2003). In addition, previous studies in SCI have demonstrated that vascular adaptations are partly reversible by electrical stimulation training of the inactive paralyzed legs in SCI (de Groot et al. 2005; Hopman et al. 2002; Thijssen et al. 2007b). These data have led some investigators to conclude that vascular adaptations observed in the paralyzed legs in SCI may primarily result from physical inactivity.
Physiological studies have been undertaken to examine the impact of inactivity on both resistance and conduit artery function and structure. These impacts of each of the models of inactivity on the function and structure of these vessel beds will be considered separately below.

\section{Resistance vessel function}

Plethysmographic measurement of change in limb volume has typically been employed as a method to assess peripheral resistance vessel function in humans (Shepherd 1983). Several limb volume techniques evolved after the initial use of plethysmography in 1905 , but all rely upon a "congesting" cuff inflated around the upper arm or thigh and inflated to approximately $40-50 \mathrm{mmHg}$ (Joyner et al. 2001). Mercury-in-silastic strain-gauges are the most frequently used technique (Whitney 1953) and were widely used in the twentieth century to examine vascular physiology and pharmacology (Joyner et al. 2001).

The majority of studies which have used venous occlusion plethysmography to assess resting blood flows have reported decreases after 4-120 days of head down tilt bed rest (26-48\%, Christ et al. 2001; Convertino et al. 1989; Louisy et al. 1997; Pawelczyk et al. 2001), 4-14 days space flight (41\%, Watenpaugh et al. 2001), 28 days limb immobilization (24\%, Bleeker et al. 2005a) and chronic spinal cord injury (26-70\%, Bleeker et al. 2005c; Hopman et al. 2002; Kooijman et al. 2003; Thijssen et al. 2007b). To gain better insight into the mechanisms responsible for these decreases in limb blood flows, Bleeker et al. examined leg vascular responses to femoral artery infusions of the nitric oxide (NO) antagonist, $\mathrm{N}^{\mathrm{G}}$-monomethyl-L-arginine (L-NMMA), the NO vasodilator sodium nitroprusside (SNP) and angiotensin II (Bleeker et al. 2005c). Studies were undertaken in SCI individuals, age-matched controls and also in healthy young men before and after 28 days of ULLS. The vasoconstrictor responses to L-NMMA and angiotensin II, and the dilator responses to SNP, were unaltered in both models of inactivity. The authors concluded that short- and long-term deconditioning preserved vasoactive responses in the lower limb skeletal muscle vascular bed (Bleeker et al. 2005c).

In another study, forearm blood flow responses to L-NMMA were examined immediately after forearm cast removal for treatment of scaphoid or Colles' fractures, and again 6 weeks after cast removal. Responses were compared to those in healthy uncasted controls. The response to L-NMMA was similar between groups and before and after 6 weeks recovery (Green et al. 1997). Although forearm injury and fracture may have influenced these results, this study suggests that physical inactivity does not influence basal activity of the NO dilator system in vivo in resistance vessels during short-term physical activity. 
Another factor that contributes to baseline vascular tone, the $\alpha$-adrenergic system, has been compared in SCI individuals and able-bodied controls (Kooijman et al. 2003). Leg blood flow changes were assessed in response to intrafemoral infusion of incremental doses of phentolamine (a competitive antagonist of the $\alpha$-adrenoceptor) during local $\beta$-adrenergic receptor blockade with propranolol. Interestingly, despite the complete spinal cord lesion in all SCI subjects, $\alpha$-adrenergic tone was not exaggerated in the leg vascular bed of SCI individuals. Recently, Thijssen et al. (2007b) examined the contribution of endothelin-1 (ET-1), a powerful endothelium-derived vasoconstrictor, to baseline blood flow in the inactive legs of SCI individuals, using intra-femoral administration of selective $\mathrm{ET}_{\mathrm{A} / \mathrm{B}^{-}}$ receptor blockers. They found a larger vasodilator response to blockade of ET-1 in the legs of SCI subjects compared with age-matched able-bodied controls, suggesting that ET-1 importantly contributes to the increased vascular tone observed as a consequence of chronic physical inactivity. To further examine this hypothesis, the authors trained their SCI subjects for 6 weeks using functional electrical stimulation (FES). After this training, the SCI subjects showed reversed ET-1-mediated vascular tone, further supporting a role for ET-1 in the increased baseline vascular tone observed in this model of deconditioning.

In a final study, which assessed resistance artery endothelial function, intra-brachial administration of endothelium-dependent (acetylcholine) and -independent (sodium nitroprusside) vasodilators was undertaken in healthy volunteers before and after 13 days of bed rest (Hesse et al. 2005). Bed rest impaired endothelium-dependent vasodilation of resistance vessels, but not smooth muscle NOmediated vasodilation. These short-term effects of bed rest were not present when bed rest was performed under energy restriction (25\% reduction in fat intake) (Hesse et al. 2005). Furthermore, the level of actual upper limb activity change associated with bed rest (subjects were allowed to do upper limb daily activities) was not controlled. These results should therefore be interpreted with caution.

\section{Conduit artery function}

Using high resolution ultrasound, flow-mediated dilation (FMD) can be examined as a marker for conduit artery endothelial function. Assuming the occluding cuff is placed distal to the scanned artery (Doshi et al. 2001), that the period of ischemia does not exceed 5 min (Mullen et al. 2001) and that diameter responses are appropriately collected (Black et al. 2008a) and normalised (Black et al. 2008a; Pyke and Tschakovsky 2007), FMD is predominantly mediated by NO (Doshi et al. 2001; Joannides et al. 1995; Kooijman et al. 2008) and serves as a valid index of conduit artery endothelium-dependent NO function (Ganz and Vita 2003). FMD also correlates with coronary endothelial function (Takase et al. 1998, 2005). This technique is non-invasive, allows direct arterial visualisation and, in contrast to plethysmography, allows measurement of absolute arterial diameters and has a good temporal resolution (Green et al. 2002b). However, arterial diameters are critically dependent upon image quality (Logason et al. 2001), while sometimes manual analysis is used, which is subject to significant observer error (Black et al. 2008a; Celermajer et al. 1992; Hardie et al. 1997; Sonka et al. 1998). Finally, it is possible that the shear stress or flow stimulus that elicits FMD may provide some independent prognostic information (Philpott et al. 2009).

Whilst impaired endothelium-dependent NO-mediated dilator function has typically been observed in subjects with traditional cardiovascular risk factors, surprisingly, an enhanced superficial femoral artery FMD response was observed after 25 and 52 days of bed rest (Bleeker et al. 2005b), 28 days of limb suspension (Bleeker et al. 2005a) and in acute (de Groot et al. 2006a) (within 21-42 days post-injury) (de Groot et al. 2006b), as well as in chronic, SCI (de Groot et al. 2005; de Groot et al. 2004). In contrast, a recent study reported decreased posterior tibial artery FMD in SCI compared with controls (Stoner et al. 2006). However, in the latter study the occlusion cuff was placed proximal to the vessel-imaging site, an arrangement that likely results in vasodilation which is less NO-dependent (Doshi et al. 2001) than distal cuff occlusion. This methodological issue may account for this atypical finding.

Changes in brachial artery endothelial function after shorter periods of bed rest also reveal conflicting results. While 5 days of bed rest did not alter the FMD response (Hamburg et al. 2007), another study reported an increased brachial artery FMD following 7 days of bed rest (Bonnin et al. 2001). Methodological differences, such as different approaches to the detection of peak arterial diameter (Hamburg et al. 2007) and the question of whether the upper limbs are truly inactive during bed rest, may have impacted these results.

Recent studies regarding the interpretation of FMD data suggest the change in diameter should be normalized for the eliciting shear stress stimulus on the endothelial cell membrane. This approach is conceptually equivalent to the interpretation of drug responses in accordance with the administered dosage. When the superficial femoral artery FMD response of spinal cord-injured individuals was expressed as diameter change relative to the hyperemic peak shear rate, FMD responses were found to be preserved (de Groot et al. 2004) or slightly increased (de Groot et al. 2005) compared to able-bodied controls (de Groot et al. 2004). A preserved normalised FMD of the superficial femoral artery was also found after 25 and 52 days of bed 
rest (Bleeker et al. 2005b) and 4 weeks of unilateral lower limb suspension (Bleeker et al. 2005a). However, the appropriate normalization approach involves assessment of the area-under-the-curve $\left(\mathrm{SR}_{\mathrm{AUC}}\right)$ for shear rate, from the time of occluding cuff deflation to that of peak diameter attainment (Pyke and Tschakovsky 2007), rather than simply the peak shear rate following cuff deflation. $\mathrm{SR}_{\mathrm{AUC}}$ normalization is particularly appropriate under circumstances where diameter responses are likely to differ as a function of the shear stress that the artery is exposed to, such as the case where arteries of differing baseline diameter are compared (e.g., SCI vs. controls). Using a 0-40 s time window to calculate the AUC, a similar FMD response was observed in SCI and able-bodied controls (Kooijman et al. 2008).

A possible explanation for the apparently preserved FMD response in deconditioned vessels may relate to upregulation of smooth muscle cell sensitivity to NO, possibly initiated as a counter-regulatory response to chronic decreases in endothelial shear stress and down-regulation of eNOS in the deconditioned vessels. Increased NO smooth muscle sensitivity to NO donors was observed after 28 days limb suspension (Bleeker et al. 2005a) and after 52 days of bed rest (Bleeker et al. 2005b). In SCI subjects, the superficial femoral artery endothelium-independent dilatation varies between 15.6 and $19.6 \%$ (de Groot et al. 2004; Thijssen et al. 2005), while healthy young controls demonstrate a dilatation of $10.9-13.4 \%$ (de Groot et al. 2004; Thijssen et al. 2006). Nevertheless, differences between these groups did not achieve statistical significance (de Groot et al. 2004).

These data go some way towards supporting the notion of enhanced smooth muscle NO responsiveness as a consequence of deconditioning. However, sublingual administration of a single dose of a NO-donor, such as nitroglycerine (GTN), has important limitations relating to between subjects differences in pharmacokinetics. Recently, therefore, smooth muscle cell NO-sensitivity was examined using incremental intra-femoral doses of sodium nitroprusside (SNP) in SCI subjects and age-matched ablebodies controls. After correcting for absolute differences in artery dimensions, both groups demonstrated similar NO sensitivity of the superficial femoral artery (Thijssen et al. 2008a).

Taken together, the results of recent studies that examined acute (21-52 days) and chronic (longer than 6 months) deconditioning suggest that endotheliumdependent and -independent vasodilation are preserved in peripheral conduit arteries. A possible explanation for the preserved conduit artery endothelial function after physical inactivity may relate to compensatory changes in conduit artery dimensions. As a result of the changes in shear rate, deconditioning induces an inward remodelling of conduit arteries and a new equilibrium is set that preserves or normalizes the vascular function. These considerations are discussed further below. Currently no information is available regarding coronary vascular function after deconditioning.

\section{Resistance vessel remodelling}

Peak reactive hyperemic blood flow assessment is an approach traditionally used to assess remodelling of resistance vessels in humans (Conway 1963; Folkow et al. 1958; Patterson and Whelan 1955; Zelis et al. 1968; Folkow 1978; Takeshita and Mark 1980; Sinoway et al. 1986, 1987; Martin et al. 1990; Silber et al. 1991; Silber and Sinoway 1990). Reactive hyperemic blood flow through the superficial femoral artery in response to a 5 min ischemic stimulus decreased by $28 \%$ after 52 days of bed rest (Bleeker et al. 2005b). A 31\% decrease was observed in the forearm vascular bed after 14 days of bed rest using a $10 \mathrm{~min}$ ischemic stimulus (Shoemaker et al. 1998). After 29 days of cast immobilization of the wrist as a treatment of bone fracture, minimal resistance during reactive hyperemia was higher in the casted than in the control arm. During the recovery period, minimal resistance during reactive hyperemia decreased in the casted arm but did not change in the control arm (Silber and Sinoway 1990). Similar findings were reported in the calf directly after 2-12 weeks of cast treatment for leg trauma and after a 6 week recovery period (Kroese 1977).

Although not significant, a trend towards decrease in hyperemic flow was present after 28 days of lower limb immobilization (Bleeker et al. 2005a) and during the first 6 weeks after a spinal cord injury (de Groot et al. 2006a, b). Reactive hyperemia is $40-60 \%$ lower in the legs of SCI compared with controls (de Groot et al. 2004). In summary, reactive hyperemic blood flow, an index of resistance vessel structure or cross-sectional area, is reduced after a period of inactivity in most models of deconditioning.

\section{Conduit artery remodelling}

Shear stress plays an important role in the regulation and adaptation of large arteries. Langille and O'Donnell established that changes in vessel structure occur secondary to chronic changes in flow, and that such changes are dependent upon the release of a labile factor from endothelial cells (Langille and O'Donnell 1986). This conclusion was later confirmed by studies demonstrating that arterial remodelling is shear stress and NO-dependent (Tuttle et al. 2001) and acts in a manner which homeostatically regulates wall shear (Tronc et al. 1996).

Baseline shear levels were found to be almost doubled in the femoral artery of chronic SCI individuals compared 
with able-bodied subjects (De Groot et al. 2003, 2004), while shear rate levels were also significantly increased after 28 days ULLS (Bleeker et al. 2005a). Several models of physical inactivity of different duration demonstrated that these increases in shear rate associated with deconditioning were not due to increases in blood flow (Bleeker et al. 2005a, b, c; de Groot et al. 2006a, b; Olive et al. 2003). The principal reason for elevated shear rate in deconditioned conduit arteries is therefore related to decreased conduit artery diameter and the consequent increase in velocity. Deconditioning induced a $6 \%$ reduction in artery diameter after 7 days of leg casting (Sugawara et al. 2004), a 13\% decrease after 28 days ULLS (Bleeker et al. 2005a), 13 and 17\% reductions after 25 and 52 days of bed rest (Bleeker et al. 2005b), respectively, a $25 \%$ decrease 18 days after a spinal cord lesion (de Groot et al. 2006b) and 30\% reduction in vessel diameter in chronic SCI (De Groot et al. 2003, 2004, 2006a; Huonker et al. 2003). Hence, conduit artery diameter decreases markedly in response to physical inactivity, which coincides with a marked increase in conduit artery shear rate.

In a previous cross-sectional study in chronic SCI individuals and able-bodied controls, Olive et al. (2003) reported that the significantly smaller femoral vessel diameter in SCI was no longer different when diameter was expressed per unit muscle mass. Interestingly, when changes in vascular properties and limb volume during the first 6 weeks after a spinal cord injury were examined (de Groot et al. 2006b), femoral artery size decreases substantially, while a simultaneous decrease in limb volume was evident. Although changes in limb volume do not completely reflect changes in muscle mass, the corrected femoral artery diameter for limb volume showed no differences over the 6 week time period and values in SCI were comparable with control values (de Groot et al. 2006b). These findings suggest a link between vascular structural adaptations and muscle atrophy as a consequence of inactivity.

The above studies have reported baseline conduit artery diameter as an index of vascular structure. However, baseline diameter reflects competitive functional influences on vascular tone, in addition to artery size. The use of baseline diameter as an index of structure is therefore polluted by factors which regulate vascular function. The importance of measuring maximal conduit artery diameter as a marker of structural changes has recently been emphasized (Naylor et al. 2005). Vasodilatation to nitroglycerin represents near maximal diameter (Naylor et al. 2005) and can therefore reflect the limits of arterial structure and size. Maximal femoral artery diameter decreased by $9 \%$ after 4 weeks of limb suspension (Bleeker et al. 2005a), 16\% after 25 and 52 days of bed rest (Bleeker et al. 2005 b) and by $35 \%$ in chronic SCI individuals (De Groot et al. 2003, 2004, 2006a). These findings reinforce those above and indicate that inactivity is indeed associated with arterial structural remodelling and decreased conduit artery dimension.

Time-course of vascular adaptations to inactivity

In a recent longitudinal study by de Groot et al. (2006b), conduit artery characteristics and limb volume were examined in SCI subjects during the 6 weeks immediately following spinal cord injury. Interestingly, the femoral artery diameter decreased substantially and rapidly, with a decrease in diameter 3 week post-injury which approached vessel dimension of chronic SCI subjects (de Groot et al. 2006b). Other models of deconditioning have also been used to establish that rapid and extensive changes occur in conduit artery dimensions (Bleeker et al. 2005a, b; Sugawara et al. 2004). These findings indicate that physical inactivity provides a strong stimulus for rapid structural remodelling of human conduit arteries. Whether these changes in conduit artery dimension parallel changes in other vascular beds, and whether functional and structural changes have a similar time-course, is discussed below.

\section{Resistance versus conduit vessels}

Evidence suggests that resistance and conduit vessels have a different time-course of adaptation to deconditioning. For example, the rapid decrease in femoral artery dimension after SCI was not accompanied by a simultaneous rapid decrease in reactive hyperemic flow, the latter a reflection of arteriolar structural changes (de Groot et al. 2006b). Parallel to this, a large decrease in conduit artery diameter during 52 days bed rest was present in the first 4 weeks, with little change thereafter, while the reactive hyperemia response did not change significantly (Bleeker et al. 2005a, b). This suggests that the mechanisms and time-course of structural vascular adaptation to deconditioning may differ between conduit and resistance vessels. This hypothesis was first proposed by Laughlin et al., based on animal data (Laughlin 1995), and later also suggested for exercise training studies in humans (Green et al. 2004). Future studies should further examine the possible differences in time-course for activity-induced changes in conduit and resistance vessels.

Functional versus structural changes

The sparse data present suggest that physical inactivityinduced conduit artery structural and functional changes may differ in terms of time-course (Fig. 2). As stated above, the decrease in femoral artery dimension after a spinal cord injury was nearly complete 3 weeks 




Fig. 2 Hypothesised changes in artery function and structure (remodelling) in response to inactivity and exercise training in humans. Studies performed in both animals and humans suggest that rapid changes occur in artery function, including nitric oxide (NO) bioavailability, in response to exercise training and that these changes are superseded by arterial remodelling and normalisation of function.

post-injury, while the FMD responses demonstrated large changes between 4 and 6 weeks after the lesion (de Groot et al. 2006b). In parallel, during bed rest and limb suspension, the change in diameter dimension occurred predominantly in the initial phase, while femoral artery endothelial function showed a gradual change over time (Bleeker et al. 2005a; Bleeker et al. 2005b). Future studies that utilize more frequent functional and structural measurements within the same vascular bed during deconditioning will provide greater insight into the time-course of structural and functional adaptation in resistance and conduit vessels.

\section{Local versus systemic adaptations to physical inactivity}

Experimental models in which the whole body is subject to physical inactivity, for example spaceflight or bed rest, are associated with vascular changes throughout the body (Bleeker et al. 2005b; Bonnin et al. 2001; Louisy et al. 1997; Zhang 2001). It must be borne in mind, however, that inactivity is also associated with changes in systemic cardiovascular parameters (Hamburg et al. 2007). In contrast, models which utilise localized physical inactivity, for example ULLS and cast immobilisation, are associated with vascular adaptations specific to the immobilized region or limb only (Bleeker et al. 2005a, b; Sugawara et al. 2004), in the absence of change in systemic cardiovascular risk factors. SCI subjects demonstrate marked vascular adaptations in the inactive, paralyzed legs (de Groot et al. 2004; Stoner et al. 2006), while upper extremity vascular function and structure are comparable with able-bodied controls (de Groot et al. 2004, 2005;
Physical inactivity is associated with rapid changes in arterial diameter, with structural remodelling occurring within weeks of, for example, spinal cord injury. There is little evidence for longer term vascular dysfunction in response to inactivity. Changes in artery function and structure occur rapidly in response to activity and inactivity

Hopman et al. 2002; Stoner et al. 2006). This raises one final consideration, pertinent to the models of inactivity used in humans. Using ULLS or a cast to immobilize one limb forces volunteers to use crutches for locomotion. Whether, on balance, this leads to a training effect in the "unaffected" weight-bearing limb, or a small deconditioning because of the global reduction in levels of physical activity, is unknown. Similarly, it is likely that a different level of activity is present in the upper extremities of SCI individuals after the lesion. The dependence on the upper limbs for locomotion may theoretically result in SCI subjects exhibiting vascular adaptations, compared with ablebodied controls, yet studies consistently indicate that nonimmobilized areas do not demonstrate enhanced vascular function or structure (Bleeker et al. 2005a; de Groot et al. 2004; Stoner et al. 2006; Thijssen et al. 2005). Taken together, available evidence indicates that physical inactivity appears to lead to localized vascular adaptations in the affected inactive regions only.

Physical inactivity, vascular adaptations and cardiovascular risk

As mentioned in the introduction, the impact of physical inactivity on traditional risk factors may not adequately explain the increased cardiovascular mortality associated with deconditioning, particularly in SCI subjects. It is therefore feasible that direct effects of inactivity on vascular structure and function, rather than the indirect effects of traditional risk factors, may explain the increased cardiovascular risk associated with a sedentary life style. However, current data, discussed above, suggests that 
deconditioning does not impair vasodilator function. It remains possible that other vascular parameters, such as intima-media thickness (Simon et al. 2002) or arterial stiffness (O'Rourke 1999) which correlate with cardiovascular risk, are abnormal in inactive subjects. To date, these parameters have only been examined using shortterm deconditioning (2-7 days) and, perhaps predictably, no changes were reported in these longer-term markers of vascular adaptation (Pannier et al. 1998; Sugawara et al. 2004). SCI subjects, however, demonstrate a lower arterial compliance (de Groot et al. 2005). Some evidence exists for enhanced vasoconstrictor function in models of inactivity, including exaggerated endothelin-1 responses (Thijssen et al. 2007b). Data regarding the impact of physical inactivity on sympathetic-mediated vasoconstrictor tone is scant.

Despite the sparse and dispersed data, and the various models of inactivity that have been adopted, it remains likely that changes in conduit and resistance vessel structure and function may help to explain the increased cardiovascular mortality and morbidity associated with deconditioning. Future studies are necessary to further examine this interesting hypothesis.

Remarkably, despite the epidemiological evidence linking physical inactivity and increased cardiovascular risk and the general acceptance of physical inactivity as a cardiovascular risk factor (USDHHS 1996), no physiological studies have ever examined the direct impact of physical inactivity on coronary artery function and structure.

\section{Effects of exercise or cardiopulmonary fitness on vascular events}

The Health Professional's Follow-up Study (HPFS) (Tanasescu et al. 2002) included analysis of 44,452 men who had their leisure time physical activity assessed by questionnaire every 2 years between 1986 until 1996. The relative risk of $\mathrm{MI}$, comparing the highest and lowest total exercise volume quintiles, was $0.7 \quad(P<0.001)$. The authors concluded that a significant inverse dose relation exists between total physical activity and CHD risk, that exercise intensity is associated with risk reduction and that the addition of "weight" training may be beneficial in terms of further risk reduction. Although studies such as the HPFS are prospective and undertaken in large cohorts, they rely heavily on self-report of physical activity and are therefore subject to misclassification bias. The Aerobics Center Longitudinal Database (ACLD) estimated $\dot{V} \mathrm{O}_{2} \max$ following graded exercise testing in 25,341 men and 7,080 women between 1970 and 1989 (Blair et al. 1996). Increased relative risk of $\mathrm{CV}$ mortality was associated with low levels of fitness $(R R=1.70)$, cigarette smoking $(\mathrm{RR}=1.57)$, elevated systolic blood pressure $(\mathrm{RR}=1.34)$ and elevated serum cholesterol $(R R=1.65)$ in men. Higher levels of cardiorespiratory fitness were associated with significant protection from the impact of other risk factors. Notwithstanding the important distinction between cardiorespiratory fitness and exercise training, this prospective data provides evidence for the $\mathrm{CV}$ benefits of exercise for primary prevention of $\mathrm{CV}$ disease.

There is no evidence available from large prospective cohort trials regarding the effect of exercise in a secondary prevention setting, although Myers et al. concluded that, after adjustment for age, peak exercise capacity measured in METs is the strongest predictor of the risk of death among both normal subjects and those with established cardiovascular disease (Myers et al. 2002). A series of meta-analyses performed on smaller studies of exercise-based cardiac rehabilitation have estimated the benefits in terms of reduction in total and cardiac mortality at between 20 and $32 \%$, relative to usual care (Taylor et al. 2004), although earlier analyses included studies performed prior to the widespread adoption of contemporary lipid-lowering, antihypertensive and interventional strategies. The most recent meta-analysis, which included 48 eligible studies to March 2003 involving 8,940 patients, attempted to address this concern. Cardiac rehabilitation was associated with significant decreases in the odds ratio for all-cause and cardiac mortality $(\mathrm{OR}=0.74)$ and the authors concluded that recent trials conducted in the era of contemporary cardiovascular therapies and case mix (post-angioplasty, CABG etc.), continued to report similar or greater benefits $(\mathrm{OR}=0.62)$. An interesting aspect of this analysis, which confirms previous findings (Ebrahim et al. 2006), was the suggestion that studies involving exercise training alone $(\mathrm{OR}=0.76)$ exert a similar effect to those studies which involved "comprehensive" rehabilitation $(\mathrm{OR}=0.84)$ consisting of behavioural strategies aimed at decreasing the impact of other $\mathrm{CV}$ risk factors. This suggests that exercise is an important component of cardiac rehabilitation programs and also indirectly suggests that modification of risk factors may not be the primary means by which exercise exerts its beneficial effect.

In summary, exercise or physical fitness is associated with an approximate $30 \%$ benefit in terms of decreasing the risk of cardiac events. Indeed, some expert opinion has stated that the most physically active individuals demonstrate CAD rates half those of the most sedentary and that in many studies the lower frequency of CAD is independent of other known atherosclerotic risk factors (Thompson et al. 2003). As described above, exercise training improves vascular function in the absence of changes in lipid levels (Lewis et al. 1999), blood pressure (Higashi 
et al. 1999a), glucose tolerance, or BMI (Watts et al. 2004a). In addition, a recent study reported significant improvements in both conduit and resistance vessel endothelial function, in the absence of change in plasma lipids, blood pressure, blood glucose, waist:hip or BMI, with no significant correlations between changes in any of these risk factors and the improvements in vascular function (Green et al. 2003). These studies indicate that improvement in risk factors is not an obligatory requirement for improvement in vascular function as a result of exercise training. Direct effects of exercise on the vasculature, perhaps by virtue of a repetitive impact of shear stress, pulse pressure or pulsatility, may therefore contribute to the reduction in coronary events associated with exercise training (Green et al. 2008c).

\section{Effect of exercise training on vascular function}

Different modalities of exercise exert distinct physiological and health benefits. For example, recent studies indicate that exercise involving different volumes of muscle mass or exercise intensity may be associated with different shear stress mediated impacts on vascular function (Goto et al. 2003, 2004, 2005; Thijssen et al. 2009). Aerobic exercise involving large muscle groups is associated with systemic changes in pulse pressure and heart rate which generate a recurrent hemodynamic (shear) stress that may directly induce vascular function and structure adaptation (see below) (Green et al. 2004, 2005), whereas small muscle group exercise is not associated with such hemodynamic signals and provides insight into localised effects of exercise independent of central regulatory or neural changes. A further consideration relates to the types of study designs adopted. Many "exercise training" studies have relied upon cross-sectional comparisons of subjects with high and low cardiorespiratory fitness as a model of the physiological impact of chronic exercise in humans. Despite efforts to match subject groups for numerous confounders (age, sex, body composition, risk factor profiles etc.), there remains the strong possibility that between-subject differences pollute the purported effects of "exercise" on vascular outcomes. Furthermore, whilst cross-sectional comparisons to some extent reflect the impact of different fitness levels on outcome measures, such differences cannot validly be ascribed to the impact of exercise training per se, since genetic cardiopulmonary capacities are included in fitness measures. In any event, the best assessment of the impact of exercise training on vascular outcome measures is derived from longitudinal training studies where within subject changes in fitness following an exercise training intervention are the focus.
Small muscle group exercise

\section{Resistance vessels}

Studies of handgrip exercise training were initially undertaken as a physiological model of the impact of localised muscle activity on vasomotor control, in the absence of marked changes in central hemodynamics during the training stimulus. Two of the three studies undertaken in healthy subjects failed to demonstrate improvement in forearm blood flow responses to ACh, SNP or LNMMA infusions (Bank et al. 1998; Franke et al. 1998; Green et al. 1994), whilst two of the three studies in heart failure demonstrated improvement in endothelium-dependent responses (Bank et al. 1998; Hambrecht et al. 2000a; Katz et al. 1997). The disparate findings both derived from a single study (Bank et al. 1998). In general, the impact of localised exercise training on resistance vessel function has not been thoroughly studied in humans and recent investigations have focussed on more clinically applicable, large muscle group, training modalities.

\section{Conduit arteries}

Studies which have examined the impact of small muscle group exercise on conduit artery function have been performed in CHF subjects (Hambrecht et al. 2000a; Hornig et al. 1996) and hypertensives (McGowan et al. 2006a). Hornig et al. (1996) performed an early study in which radial artery FMD was enhanced after 4 weeks of handgrip training and this improvement was NO mediated as indicated by its abolition using NO blockade. Hambrecht et al. (2000a) also demonstrated that hand grip exercise training, particularly with the addition of L-arginine supplementation, enhanced ACh mediated radial artery diameter change. These studies have some clinical relevance in $\mathrm{CHF}$, as they suggest that vascular adaptations which favour enhanced $\mathrm{O}_{2}$ delivery and decreased peripheral resistance are possible as a consequence of small muscle group exercises which can reverse the peripheral abnormalities which may limit functional capacity in such subjects, without the hemodynamic burden associated with more systemic forms of training. Finally, McGowan recently observed enhanced brachial FMD responses after isometric hand grip exercise in patients with primary hypertension (McGowan et al. 2006a; b).

Large muscle group dynamic exercise

\section{Resistance vessels}

There have been at least 12 studies of whole body exercise programs (e.g., running, walking, cycling) in healthy 
control subjects either as a primary intervention group or as matched controls in studies of subjects with cardiovascular disease. The outcomes in terms of improvement in resistance vessel function are mixed. In young subjects who undertook cycle exercise training, some improvement in basal NO function was observed after brachial LNMMA infusions, but no changes in stimulated endothelial function were evident (Kingwell et al. 1997b). Another study of fit young men who undertook high intensity training found a decrease in ACh and LNMMA responses (Bergholm et al. 1999). In middle aged subjects, exercise training enhanced ACh responses in two studies (DeSouza et al. 2000; Higashi et al. 1999a), but failed to do so in a third (Maiorana et al. 2001b). Finally, a recent study suggested that basal NO bioavailability is enhanced with training in middle aged and older subjects, an adaptation to some extent counteracted by sympathetic vasoconstrictor tone (Sugawara et al. 2007).

Whilst there is no apparent consensus regarding the impact of exercise training on resistance vessel function in healthy subjects, the majority of studies performed in subjects with impaired endothelial function have documented improvements. This includes studies in patients with CHF (Hambrecht et al. 1998; Linke et al. 2001; Maiorana et al. 2000b; Parnell et al. 2005), hypertension (Higashi et al. 1999a, b), hypercholesteremia (Lewis et al. 1999; Walsh et al. 2003b), obesity (Sciacqua et al. 2003; Watts et al. 2004a) and diabetes (Maiorana et al. 2001a). Indeed, there are no published studies in this category that we are aware of that have not reported improvements in resistance vessel vasodilator function as a result of large muscle group training.

Finally, a recent study investigated the effects of both chronic training and short term exercise in older subjects on microvascular function using microdialysis and laser Doppler flow assessments in the skin (Black et al. 2008b). Exercise was associated with enhanced NO-mediated skin vasodilator responses to both $\mathrm{ACh}$ infusions and local heating stimuli in this study.

\section{Conduit arteries}

One study of conduit artery responses in healthy subjects indicated that training of army recruits increased brachial FMD (Clarkson et al. 1999) and another suggested improvements after 4 weeks training (Pullin et al. 2004). However, resistance exercise training did not alter brachial responses (Rakobowchuk et al. 2005) in healthy volunteers and cycle training had no impact in older subjects (Moriguchi et al. 2005; Thijssen et al. 2007a).

In subjects with $\mathrm{CV}$ disease or risk factors, the majority of studies indicate that exercise training involving a large muscle mass induced enhanced conduit artery function.
Studies undertaken in CHF (Belardinelli et al. 2006; Hambrecht et al. 2003; Linke et al. 2001; Wisloff et al. 2007), CAD (Edwards et al. 2004; Gokce et al. 2002a; Walsh et al. 2003a), peripheral artery disease (Andreozzi et al. 2007), hypertensives (Moriguchi et al. 2005; Westhoff et al. 2007), hypercholesterolemics (Walsh et al. 2003b), diabetics (Fuchsjager-Mayrl et al. 2002; Lavrencic et al. 2000; Maiorana et al. 2001a) (Xiang and Wang 2004) and subjects with obesity (Meyer et al. 2006; Olson et al. 2006; Sciacqua et al. 2003; Watts et al. 2004a, b; Woo et al. 2004) have also demonstrated enhanced FMD responses following different exercise training programs. Whilst a few studies exist which have not observed changes in conduit artery function following whole body exercise regimes (Gokce et al. 2002b; Paul et al. 2007), data in conduit arteries fundamentally reinforces the findings described above in resistance vessels, suggesting that vascular function is more amenable to enhancement in subjects with cardiovascular disease and risk factors who may exhibit impaired vasomotor and endothelial function $a$ priori, than in healthy subjects with less impaired vascular function at the outset.

\section{Summary: conduit and resistance arteries}

The use of small muscle group exercise training provides information regarding the impact of localised muscular activity, in the absence of marked change in central hemodynamics, on vascular adaptation. Conversely, larger muscle mass exercise involves both a localised stimulus in the active muscle, and systemic hemodynamic stimulus by virtue of both increases in cardiac output and peripheral changes in the sympathetic vasomotor tone sub-serving the control of blood flow and distribution. It is clear that these forms of exercise represent disparate stimuli in terms of their impact on endothelial shear stress (Green et al. 2005) and it is likely that some of the differences observed in terms of training effects in response to small and large muscle mass exercise reflect these differences.

No clear consensus emerges from the studies reviewed above regarding the impact of exercise training in healthy volunteers, possibly because of the disparate nature of the subjects studied or the various forms of exercise interventions applied. Conversely, most studies indicate that subjects with CV disease and risk factors benefit from exercise training. An explanation for some of the disparate findings may relate to the type or form of exercise used and in particular the intensity of exercise (Goto et al. 2003; Green et al. 2008c; Wisloff et al. 2007). In this context, the study of Goto et al. is revealing, in that it suggests that low intensity exercise may fall below the threshold required for vascular adaptation in healthy subjects, whilst moderate intensity exercise is associated with improvements in 
endothelial function. Exercise at higher intensity (Bergholm et al. 1999; Goto et al. 2003) may be associated with elevated levels of oxidative stress and inflammatory responses after exercise and this may, in turn, diminish any underlying shear and hemodynamic-mediated beneficial adaptations (Laughlin et al. 2008).

\section{Coronary vascular function}

Animal studies have convincingly demonstrated that exercise induced flow-mediated epicardial coronary vasodilation is dependent upon the integrity of the endothelium (Berdeaux et al. 1994; Niebauer and Cooke 1996), and experimental studies of coronary blood flows in humans indicate that NO blockade abolishes pacinginduced epicardial vessel dilation, indicating that NO contributes to vasodilation in these conduit vessels in patients free of CAD risk factors (Quyyumi et al. 1995) and in those with angiographically normal coronary arteries (Tousoulis et al. 1997). NO is also involved in pacing-induced hyperemia in patients with risk factors for CAD, including some with mildly irregular arteries (Duffy et al. 1999), whilst NO production increased by pacing was abolished at the sites of stenoses in patients with CAD disease (Tousoulis et al. 1997). These studies strongly indicate that acute exercise is associated with changes in endothelial function and, furthermore, that repeated exercise stimuli (i.e., training) which may induce chronic change in vascular function and also structure. It is important to note that animal studies suggest that coronary arteries of different caliber possess differences in eNOS content and NO-related adaptations to exercise training may be vessel caliber dependent. Larger vessels, which are exposed to higher shear stress forces, possessing greater capacity for NO production (Green et al. 2004; Laughlin et al. 2003a; Laughlin et al. 2003b). Laughlin has previously expertly reviewed evidence regarding vascular adaptations to exercise training in conduit and resistance vessels of animals (Jasperse and Laughlin 2006; Laughlin and McAllister 1992).

In humans, several important studies have indicated a beneficial impact of exercise training on coronary vasodilator and endothelial function. Hambrecht et al. studied 19 stable CAD patients randomised to exercise training or control groups for a period of 4 weeks (Hambrecht et al. 2000b). Intra-coronary infusion of $\mathrm{ACh}$ and adenosine were used to assess epicardial coronary artery endothelium-dependent vasodilator function and resistance vessel function, respectively. Quantitative angiography and Doppler flow-wires assessed coronary diameter and flow. Training improved $\mathrm{ACh}$ and adenosine responses, indicating that coronary conduit and resistance artery endothelium-dependent vasodilator function was enhanced by exercise. In a subsequent study, the authors found that home-based exercise training sustained part of the effects of this hospital-based intervention (Gielen et al. 2003). These authors also completed a comprehensive study which concluded that exercise training improves endothelial function in vivo by upregulating NO synthase protein expression and by increasing phosphorylation of NO synthase, effects consistent with a shear-stress mechanism for enhanced NO bioactivity with training (Hambrecht et al. 2003) (see "Mechanisms responsible for change in vascular function and structure").

Effect of exercise training on sympathetic nervous system and vasoconstrictor function

Exercise training may alter autonomic balance in a manner which decreases cardiovascular risk. Increased parasympathetic, and decreased sympathetic, outflow to the heart would typically be cardioprotective (Billman and Kukielka 2006). Low heart rate variability is a prognostic index of cardiovascular mortality (Dekker et al. 1997; Gerritsen et al. 2002; Tsuji et al. 1994). Some studies suggest that exercise training enhances heart rate variability (Buchheit et al. 2005; Davy et al. 1998; Levy et al. 1998; Rennie et al. 2003; Wichterle et al. 2004), possibly by increasing large artery compliance (Hunt et al. 2001; Tanaka and Swenson 1998), including that of the carotid sinus and aortic arch. This, in turn, may increase baroreceptor nerve traffic and increase parasympathetic tone. Alternatively, exercise training may lead to brain stem cardiorespiratory center remodelling which reduces sympathetic and enhances parasympathetic outflow (Billman and Kukielka 2006; Nelson et al. 2005).

Direct evidence for changes in sympathetic nervous system (SNS) mediated control of the vasculature after exercise training is lacking. It has been pointed out (Rowell 1993) that training is associated with large increases in cardiac output (stroke volume), whereas mean arterial pressure does not markedly change. A substantial increase in vascular conductance therefore occurs to accommodate the increase in output that accompanies training. Whilst this increase in conductance may result from enhanced vasodilator function ("Effect of exercise training on vascular function") or arterial remodelling ("Effect of exercise on training on vascular structure"), another possibility is that SNS-mediated vasoconstrictor tone decreases with training. Ray et al. reviewed the few available studies relating to muscle sympathetic nerve activity (MSNA) and exercise and concluded that MSNA may decrease with training (Ray and Hume 1998). Galbo (1983) also suggested that norepinephrine (NE) spillover decreases at matched absolute workloads following training. However, it has also been suggested that MSNA and NE spillover do 
not change after training when expressed in relative terms (Rowell et al. 1996). This suggests that SNS withdrawal is not responsible for the enhanced conductance evident following training (Green et al. 2008b). In addition, Tanaka et al. recently reported enhanced vasodilation in response to phentolamine infusion following training, suggestive of increased SNS-mediated vasoconstriction (Sugawara et al. 2007). This, and the previous findings of Haskell et al. (1993), suggest that basal vasoconstriction may, in fact, increase following training.

The impact of exercise training on locally produced and circulating vasoconstrictors such as ET-1 and angiotensin II (Ang II) has not been thoroughly researched (Thijssen et al. 2008b). Data derived from exercise-trained swine suggest that training improves aortic and coronary sensitivity to the vasoconstrictor ET-1 (Jones et al. 1999) and lowers ET-1 DNA expression (Wamhoff et al. 2002). In humans, two recent studies have reported that exercise training partly reverses increased ET-1-mediated vascular tone in the leg (Thijssen et al. 2007c) and forearm (Van Guilder et al. 2007) of older humans. Regarding Ang II, Adams et al. (2005) found that exercise training in patients with stable coronary artery disease leads to a $49 \%$ reduction in Ang II-induced vasoconstriction. Whilst the evidence relating to exercise training effects on vasoconstrictor pathways is far less comprehensive than that relating to vasodilator control mechanisms, the few studies performed in humans suggest that the contribution of vasoconstrictor pathways to vasomotor control may decrease after training.

\section{Effect of exercise training on vascular structure}

Autopsy and angiographic studies performed in athletes (Currens and White 1961; Pelliccia et al. 1990) and physically fit individuals (Hildick-Smith et al. 2000; Mann et al. 1972; Rose et al. 1967) suggest that physical conditioning induces an increase in arterial cross sectional area, also referred to as "arterial remodelling". Similarly, cross-sectional studies have consistently reported enlargement of skeletal muscle conduit (Ben Driss et al. 1997; Dinenno et al. 2001; Huonker et al. 1996, 2003; Kool et al. 1991; Schmidt-Trucksass et al. 2000; Wijnen et al. 1991; Zeppilli et al. 1995) and resistance (Green et al. 1996; Sinoway et al. 1986) vessels in athletes relative to matched controls, indicating that exercise training may induce arterial enlargement (Prior et al. 2003). Findings from animal studies regarding epicardial and resistance coronary vasculature concur (Brown 2003). The studies described below have primarily utilised longitudinal designs in which subjects were followed across a training program.
Resistance vessel remodelling

Sinoway et al. performed two of the earliest studies which specifically addressed the question of the impact of exercise training on resistance vessel "structure". They measured blood flow responses using stain-gauge plethysmography and utilised a metabolic stimulus (ischemia or ischemic exercise) to achieve maximal, or peak, forearm blood flow responses. By using a stimulus that induced peak localised dilation (Patterson and Whelan 1955; Takeshita and Mark 1980), without inducing reflex changes in vasomotor control, they sought to assess the impact of exercise training on structural vascular adaptations, independent of central regulatory changes. As mentioned above, maximal or peak blood-flow responses in response to ischemic stimuli have commonly been used to assess resistance vessel structural adaptations in various settings (Conway 1963; Folkow et al. 1955; Sivertsson 1970), based on the assumption that peak reactive hyperemia in response to a maximal vasodilator diminishes the impact of functional differences between subjects or following interventions (Patterson and Whelan 1955; Takeshita and Mark 1980). Peak reactive hyperemic stimuli used in this context include 10 minutes of limb ischemia; the blood flow response to which cannot be increased by co-infusion of vasodilator agents (Takeshita and Mark 1980). More recently, periods of ischemia combined with ischemic exercise have been utilized to induce peak blood flow responses (Naylor et al. 2005). While plethysmography has commonly been used for peak blood flow assessment, Doppler ultrasound methodology can also be used to directly measure blood flow through conduit arteries in humans (Green et al. 2002b; Hughson et al. 1996, 2001; Radegran 1997; Radegran and Saltin 1998, 1999) at a higher temporal resolution (Naylor et al. 2005).

Sinoway et al. demonstrated that the preferred arms of tennis players exhibit much higher peak vasodilator responses to 5 and $10 \mathrm{~min}$ periods of forearm ischemia + exercise than the non-preferred limbs of these athletes or either limb of non-tennis playing control subjects (Sinoway et al. 1986). A subsequent study demonstrated that 4 weeks of hand-grip exercise training significantly enhanced the peak dilator response to a $10 \mathrm{~min}$ period of forearm ischemia in the trained, but not untrained, contralateral forearm (Sinoway et al. 1987). The authors concluded that exercise training enhances the intrinsic ability of skeletal muscle resistance vessels to dilate (Clausen et al. 1973; Gleser 1973; Saltin et al. 1976; Yasuda and Miyamura 1983). The findings were unlikely to result from changes in sympathetic tone, as Takeshita and Mark demonstrated that peak blood flow responses following 10 min ischemic stimuli were not altered by lower body negative pressure induced increases in sympathetic outflow (Sinoway et al. 1986; Takeshita and Mark 1980). In 
addition, Klausen et al. (1982) had previously demonstrated that, when cardiac output is not a limiting factor during leg exercise, training is associated with increased maximal leg blood flows due to enhanced vasodilator capacity.

The increases in peak vasodilator capacity observed by Sinoway were also not associated with muscle hypertrophy, as the training program did not alter maximal workload performed or forearm circumference, and because plethysmographic flow responses are normalised to $\mathrm{dL}$ of forearm tissue (Sinoway et al. 1986, 1987). Finally, training-induced increases in skin blood flow were discounted, as an index of skin blood flow did not change with training (Sinoway et al. 1987).

The enhanced intrinsic vasodilator capacity of active muscle beds following training may conceivably result from the well established increase in capillary density that occurs with training (Andersen and Henriksson 1977). However, as explained by Snell et al. (1987), muscle blood flow may not predominantly depend upon capillary density (Maxwell et al. 1980). Whilst capillaries regulate transit time and $\mathrm{O}_{2}$ extraction, they contribute much less resistance to flow than upstream arterioles (Brown 2003; Kassab et al. 1993; Laughlin and Ripperger 1987). In addition, electrical stimulation experiments suggest that the time-course of adaptation in capillary density (rapid $\sim 4$ days) (Brown et al. 1976) is dissociated from adaptations in hyperemic flows (14-28 days) (Hudlicka et al. 1977). Adaptations observed in maximal blood flow or conductance responses with training therefore most likely reflect changes in the caliber or cross-sectional area of the resistance arteries, i.e. arterial remodelling, rather than increases in capillarity (Brown 2003).

In addition to the studies of Sinoway described above, several other studies have observed increased resistance artery vasodilator capacity in response to localized small muscle group exercise training. Green et al. confirmed the Sinoway findings and added the observation that no significant change in either endothelium-dependent or -independent NO vasodilator function was apparent in trained limbs of healthy young subjects (Green et al. 1994, 1996). Martin observed enhanced maximal calf conductance following swim training in middle-aged men and women (Martin et al. 1987) and also in older subjects following walking/running exercise (Martin et al. 1990). Two studies performed in subjects with heart failure observed enhanced calf vasodilator capacity following lower limb exercise training (Demopoulos et al. 1997; Dziekan et al. 1998), whilst other studies induced increased peak common femoral artery blood flows in response to voluntary and electrically stimulated thigh exercise (Thijssen et al. 2005). Finally, some studies have reported enhanced upper limb resistance artery vasodilator capacity following predominantly lower limb exercise training interventions (Maiorana et al. 2001b; Silber et al. 1991), although the generalisability of this vascular adaptation remains somewhat controversial (Green et al. 2008a; Thijssen and Hopman 2008) ("Local versus systemic adaptations to exercise").

\section{Conduit artery remodelling}

Several cross-sectional and longitudinal studies suggest that exercise training is associated with enlargement of skeletal muscle conduit arteries in humans. In an early study which utilized M-mode echocardiography, Zeppilli et al. observed significantly increased large artery (aorta, carotid, subclavian arteries) size in endurance trained athletes, relative to matched sedentary controls (Zeppilli et al. 1995). These differences persisted after correction for body surface area differences between the athletes and controls. Wheelchair athletes demonstrated enhanced dimensions in the aortic arch and subclavian artery, but lower values in the abdominal aorta and mesenteric artery. These findings essentially extended previous reports of enlargement in conduit arteries of athletes compared to control subjects (Kool et al. 1991; Wijnen et al. 1991). Later findings by Huonker et al. suggested that larger elastic arteries (e.g., aorta) show less adaptability than smaller conduit arteries (subclavian, femoral) supplying peripheral limb muscle groups (Huonker et al. 1996, 2003; Schmidt-Trucksass et al. 2000). One of these studies observed diminished femoral artery diameters in paraplegic subjects, as well as in the affected, but not unaffected, limbs of below-knee amputees, whereas cyclists possessed larger femoral arteries than these subjects and healthy controls and tennis players larger subclavian arteries in their racket arm than the contralateral limb (Huonker et al. 2003). Together, these cross-sectional data strongly suggest that chronic exercise training or detraining are associated with arterial remodelling. However, few of these studies corrected findings for between-subjects scaling factors which can potentially generate misleading interpretations (Naylor et al. 2008).

One way to avoid the problems associated with between-subject comparisons is to examine the impact of an exercise training intervention on skeletal muscle conduit artery adaptations. In small sample studies of healthy young men, Miyachi et al. observed significant increases in the dimensions of the ascending and abdominal aorta following 8 weeks of cycle ergometer training (Miyachi et al. 1998) and of the femoral artery in the trained, but not untrained limb, after 6 weeks of one-legged cycle exercise (Miyachi et al. 2001). These training effects were reversed following detraining (Miyachi et al. 2001). The authors concluded that regional, rather than systemic, factors are 
responsible for conduit artery remodelling as a result of training. Change in femoral artery diameter explained $70 \%$ of the variance in change in $\dot{V} \mathrm{O}_{2 \max }$ with training, reinforcing the tight nexus that exists between conduit artery remodelling and enhanced central hemodynamic adaptation to training (Klausen et al. 1982). These data also infer that exercising limb changes in shear rate, rather than systemic changes in blood pressure or artery transmural pressure, are responsible for conduit artery adaptation (Laughlin et al. 2008). Finally, in a study submitted concurrent with that of Miyachi (Miyachi et al. 2001), enhanced resting femoral artery diameter was observed following aerobic (walking) exercise training in previously sedentary men (Dinenno et al. 2001).

In all of the above studies, resting arterial diameter has been used as an index of arterial remodelling. However, resting diameter is dependent upon sympathetic nervous system tone, as well as paracrine and circulating hormonal modulation. As these competing vasodilator and constrictor influences impact upon resting tone, baseline artery diameter may not be an optimal index of vascular structure and remodelling following exercise training, a stimulus which modulates each of these factors (Naylor et al. 2005). Therefore, it has been proposed that peak artery diameter may serve as a more appropriate assessment of conduit structure (Naylor et al. 2005) than resting measurements. This suggestion is reinforced by the data of Haskell et al. (1993), who observed no differences using quantitative angiography in the cross-sectional area of coronary arteries in athletes at rest, relative to matched sedentary control subjects, despite marked increases in maximal dilator capacity in response to pharmacological stimulation (GTN). These investigators suggested that, in the basal state when myocardial $\mathrm{O}_{2}$ demand is not elevated, the coronary arteries of athletes may exhibit greater vascular tone (Haskell et al. 1993). In summary, then, a strong argument can be made that, just as assessment of resistance vessel vasodilator capacity requires the application of a peak vasodilator stimulus, studies of conduit artery remodelling should attempt to assess maximal diameter or cross-sectional areas. We recently demonstrated, at least in the brachial artery, that peak conduit and resistance vessel structure can be simultaneously assessed using ultrasound Doppler approach and a combination of ischemic exercise or pharmacological stimulation (Naylor et al. 2005). In another study, Naylor et al. observed training-induced enhancement of brachial artery diameter at rest and following a 10-min period of ischemia, thereby providing evidence for arteriogenic adaptation in response to a peak dilator stimulus (Takeshita and Mark 1980). The findings of this study in elite rowers suggest that chronic exercise induces marked arterial remodelling, and also that resumption of exercise training after a brief sojourn is also associated with further structural adaptation in highly trained individuals (Naylor et al. 2006).

\section{Coronary artery remodelling}

Training-induced adaptations in large and small coronary artery diameter in animals have been expertly reviewed by Laughlin and McAllister (1992) and Brown (2003). These reviews indicate that well-conducted exercise studies suggest increased coronary flow capacity, a measure of resistance artery structural remodelling, as well as large epicardial arterial remodelling after training.

The earliest studies regarding coronary structural adaptation in humans involved autopsy analysis. In a series of necropsy experiments (Rose et al. 1967), blind analysis of plaque free segments of the right main coronary artery internal diameter was undertaken in subjects who died from myocardial infarction and a group of "controls" who had no evidence of post-mortem infarction. All measurements were undertaken at a constant distension pressure $(80 \mathrm{mmHg})$. Subjects were classified according to whether they had been engaged in light, moderate or heavy physical activity occupations (Rose et al. 1967). The authors reported a $75 \%$ greater coronary artery diameter in control versus infarction subjects within the active and heavy physical activity occupational groups. This paper has been widely quoted in evidence that exercise is associated with coronary artery enlargement. However, whilst mean diameter in control subjects was somewhat larger $(0.1>P>0.05)$ in those engaged in "active", compared to "light" physically active occupations $(3.90$ vs $4.30 \mathrm{~mm}$ ), there was a surprising lack of effect for those in "heavy" occupations, compared to the light group (3.90 vs. $3.98 \mathrm{~mm}$ ). The majority of the difference between infarction and control subjects within each occupational category was, in fact, evident in the diameter of the infarction subjects, whose diameters were lower in the more active groups (3.82, 3.22, $2.94 \mathrm{~mm}$ for light, active and heavy). This evidence is therefore open to the interpretation that, in those with small coronary arteries, higher activity levels are associated with greater risk of infarction.

Another widely quoted paper on the impact of exercise on coronary dimensions relates to the autopsy of Clarence De Mer (Currens and White 1961), who ran 100 marathons and 1,000 distance races and won the Boston marathon 7 times. His coronary artery dimensions were quoted as being "two or three times the normal diameter". However, the cardiac findings must be considered with some caution, as the post-mortem was performed after the heart was embalmed and had a trocar passed through it in several places. Unconfirmed reports also suggest that the examination may have occurred post-exhumation (Thompson 2004). 
A final historical report relating to the impact of exercise on coronary artery size relates to autopsy studies performed on 50 tribal Masai from Tanzania and Kenya (Mann et al. 1972). The coronary intimal thickness of the older Masai exceeded that of a cohort of US subjects aged 60-69 years and there was widespread presence of atheroma, similar to that expected in American men of similar age. However, symptomatic cardiovascular disease was rare in these subjects (Mann et al. 1964) and the autopsies revealed that the coronary lumen displayed marked enlargement, such that the intimal thickening was not compromising. The Masai were remarkable fit (Mann et al. 1965) and the authors speculated that they were protected from the clinical manifestations of atherosclerosis by physical fitness, which caused their coronary arteries to enlarge.

The advent of trans-thoracic echocardiography encouraged an ambitious cross-sectional study of coronary artery size in 125 male athletes, selected from an initial sample of 625 subjects on the basis of acceptable image quality (Pelliccia et al. 1990). Using a $3.25 \mathrm{MHz}$ transducer to assess proximal epicardial diameter in the short axis view using M-mode echocardiography performed approximately $1 \mathrm{~cm}$ from the aortic ostium, these authors reported a correlation between coronary size and LV mass and wall thicknesses. A weak correlation was also evident for coronary size and $\dot{V} \mathrm{O}_{2 \max }$. The authors concluded from this correlational analysis that training-induced myocardial hypertrophy involves a proportionate increase in coronary lumen size (Pelliccia et al. 1990). A cross-sectional study performed a decade later compared distal LAD diameter and blood flow, assessed using transthoracic echocardiography, in healthy control subjects and athletes during nitroglycerine administration and intravenous adenosine infusion. The diameter increase to nitroglycerine was greater in athletes $(14.1 \%)$ than controls $(8.8 \%)$ and coronary flow reserve was also greater in the athletes. At least some of the increased flow reserve was attributed to lower resting coronary flow in athletes, associated with relative bradycardia. The increase in peak flow was similar to that in controls when data were scaled for LV mass. Although the findings of this study were limited by the use of flow reserve in the absence of differences in peak flows, the limited spatial resolution of echocardiography as a technique for imaging coronary arteries and the systemic infusion of a dilator agent which may have induced different reflex coronary responses, it nonetheless suggests that epicardial coronary diameters are increased in athletes.

A number of studies have performed quantitative angiography to assess the impact of exercise training on coronary artery structure. In the study by Haskell et al., no differences in the cross-sectional area of resting coronary arteries were observed in athletes, relative to matched sedentary control subjects, despite marked increases in maximal dilator capacity in response to nitroglycerine. The investigators concluded that the arteries of highly trained middle aged men exhibit greater dilating capacity than those who are sedentary (Haskell et al. 1993).

The intervention studies of Hambrecht et al. provide further insight. In the 10 stable CAD patients randomised to exercise training for a period of 4 weeks (Hambrecht et al. 2000b), intra-coronary infusion of $\mathrm{ACh}$ revealed higher epicardial diameter responses than controls, indicating that endothelium-dependent vasodilator function was enhanced ("Coronary vascular function"). Interestingly, the endothelium-independent epicardial dilator responses to GTN and adenosine were unaffected by training, suggesting no change in coronary conduit artery remodelling in response to this short period of exercise training. Resting arterial diameters, pre versus post intervention in each group, were not reported. Coronary velocity and flow reserve, measured using a Doppler flowwire, revealed increased coronary flow reserve responses to adenosine, suggesting enhanced vasodilator capacity of coronary resistance vessels. This study can therefore be interpreted as indicating that short-term exercise training in humans increases resistance vessel vasodilator capacity without inducing conduit artery remodelling. However, a follow-up study, involving a further 6 months of home based exercise training, reported enhanced adenosinemediated coronary flow reserve and coronary artery diameter, apparently evident at 4 weeks (Gielen et al. 2003). In a further experiment involving assessment of left internal mammary artery adaptations to 4 weeks of exercise training in patients awaiting coronary bypass graft surgery, the training group exhibited enhanced adenosineinduced diameter and peak blood flow velocity responses, suggesting increased coronary conduit and resistance artery adaptation (Hambrecht et al. 2003). There is therefore some inconsistency between these studies in terms of the reported conduit artery responses but, in general, evidence was provided for enhanced conduit and resistance vessel vasodilator capacity.

In common with the study of Haskell, no effects of exercise were reported by Hambrecht et al. in terms of resting resistance or conduit artery characteristics in the studies described above. This is further reinforced by a final experiment in which the effects of percutaneous coronary intervention with stenting (PCI) were compared to exercise training in a 12 month randomised trial of 101 male subjects. Relative to the PCI group, exercise training significantly enhanced cardiopulmonary fitness and cost approximately half as much due to fewer rehospitalisations or repeat procedures. At 12 months follow-up, the PCI group exhibited significantly increased lumen diameter $(0.53-2.57 \mathrm{~mm})$ and decreased relative stenosis diameter (80.7-11.8\%), whereas exercise training had no impact on 
arterial stenotic size $(0.66-0.69 \mathrm{~mm}, 77.9-76.5 \%)$. Despite this, there was significantly higher event-free survival in the exercise training group ( 88 vs. $70 \%$ ). The implication of this study is that, whilst coronary interventions treat only a short segment of the diseased coronary tree, exercise training exerts beneficial effects on disease progression in the entire arterial bed.

\section{Local versus systemic adaptations to exercise}

A series of studies which investigated the impact of exercise training on vascular function in humans (Maiorana et al. 2000a, b, 2001a, 2002; Walsh et al. 2003a; b; Watts et al. 2004a, b) involved a similar exercise training intervention, a combination of resistance and aerobic exercise, performed under close supervision, in which upper limb exercise was avoided. In some of these studies upper limb conduit artery function (Maiorana et al. 2001a; Walsh et al. 2003a, b; Watts et al. 2004a, b) was examined, whilst in others the resistance vessel adaptations were assayed using intra-brachial infusions of acetylcholine, sodium nitroprusside and sometimes L-NMMA. All of these studies demonstrated improvement in upper limb endothelial function following lower limb training (Green et al. 2004; Maiorana et al. 2003), despite subjects being expressly requested to avoid hand-grip exercise. Hambrecht et al. (Linke et al. 2001) also observed systemic vascular effects of lower limb exercise. In addition, a review of the literature preceding these publications (Green et al. 2004) unearthed other studies indicating improvement in upper limb vascular function as a result of predominantly lower limb exercise (Clarkson et al. 1999; DeSouza et al. 2000; Hambrecht et al. 1998; Kingwell et al. 1997b), although many of these did not report whether subjects were specifically requested to avoid incidental hand-gripping. More recent studies have largely reinforced evidence that lower limb exercise generates changes in upper limb vascular function (e.g., Clarkson et al. 1999; DeSouza et al. 2000; Fuchsjager-Mayrl et al. 2002; Goto et al. 2003; Wisloff et al. 2007; Higashi et al. 1999a; Linke et al. 2001; Maiorana et al. 2000a, 2001b; Schmidt et al. 2002; Walsh et al. 2003a, b) (Kingwell et al. 1997b) (see Table 1).

In terms of generalised effects of training on vascular structure, a number of studies have investigated the impact of leg exercise training on forearm vasodilator capacity as an index of resistance artery remodelling. Silber et al. (1991) observed a significant increase in forearm peak reactive hyperemic flows following bicycle ergometer training during which arm exercise was minimized. They concluded that vascular responses to conditioning stimuli can involve vascular beds not specifically involved in the training stimulus. They furthermore suggested that this effect may be dependent upon the mass of muscle involved in the training stimulus, as hand-grip training studies were not associated with contra-lateral limb adaptations (Green et al. 1994, 1996; Sinoway et al. 1986, 1987). Whilst some other studies involving predominantly lower limb exercise have observed evidence for upper limb resistance artery remodelling (Maiorana et al. 2000b), others have not observed such an effect (Demopoulos et al. 1997; Dziekan et al. 1998; Walsh et al. 2003b). However, some of the latter studies (Demopoulos et al. 1997; Dziekan et al. 1998) utilized a reactive hyperemic stimulus involving only $5 \mathrm{~min}$ of forearm ischemia, a stimulus which has repeatedly been demonstrated as insufficient to induce a true maximal hyperemic responses (Naylor et al. 2005; Sinoway et al. 1986; Takeshita and Mark 1980). Studies of conduit arteries have not typically observed adaptation in non-exercised regions in healthy subjects (Dinenno et al. 2001; Huonker et al. 2003; Tanaka et al. 2002).

A mechanistic explanation for generalised changes in arterial structure and function may relate to the impact of lower limb exercise on blood flow and shear stress patterns in inactive arterial beds. Shear stress provides a major physiological signal to improvement in endothelial function (Pohl et al. 1986; Rubanyi et al. 1986) and also adaptation in arterial size (Langille and O'Donnell 1986; Tronc et al. 1996; Tuttle et al. 2001). This effect is, at least in part, transduced by nitric oxide. Recent data suggests that lower limb exercise such as cycling induces a pattern of blood flow change in the brachial artery of the inactive upper limb characterized by increases in anterograde flow during systole as cardiac output increases, along with large increases in retrograde flows during diastole (Green et al. 2002b). The "amplitude" of flow and shear rate changes increases with exercise intensity (Thijssen et al. 2009). The shear stress sensitive endothelium is therefore not exposed to a smooth increase in laminar anterograde flows as lower limb exercise intensity increases, but rather, large oscillations in shear as blood is dragged in both directions across the cell membrane. This flow pattern in the brachial artery of the resting upper limb during lower limb exercise is associated with NO release (Green et al. 2002a), which in fact exceeds that associated with hand grip exercise, even when both types of exercise cause similar mean or average blood flows into the limb (Green et al. 2005). It seems, therefore, that the mode and intensity of exercise performed has important impacts on the pattern of flow, even when bulk or mean flows are similar over time (Thijssen et al. 2009). If endothelial phenotype is indeed sensitive to flow and shear stress patterns (Laughlin et al. 2008), then different types of exercise may logically result in different endothelial adaptations and, consequently, different degrees of change in the health of the vessel wall and its 


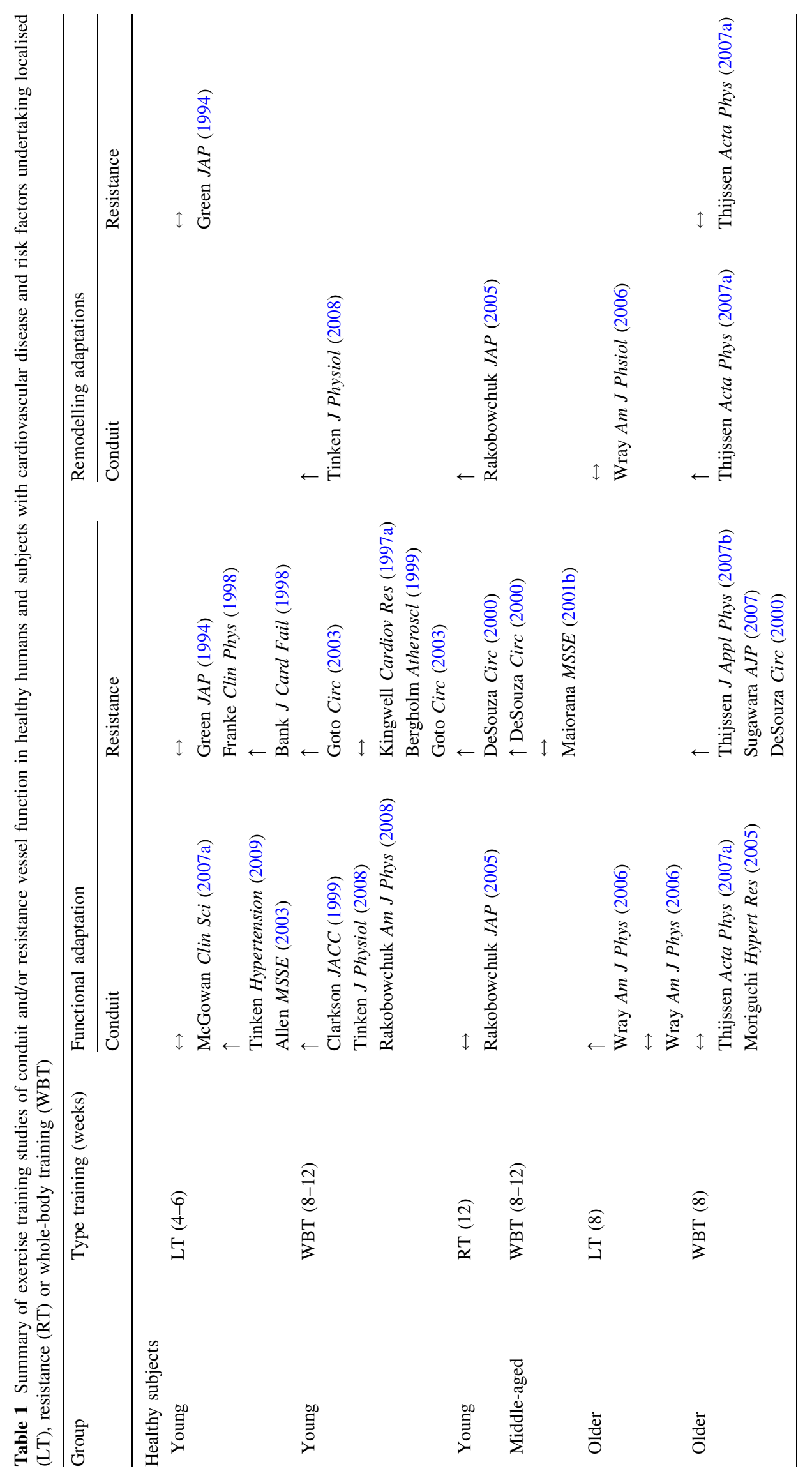




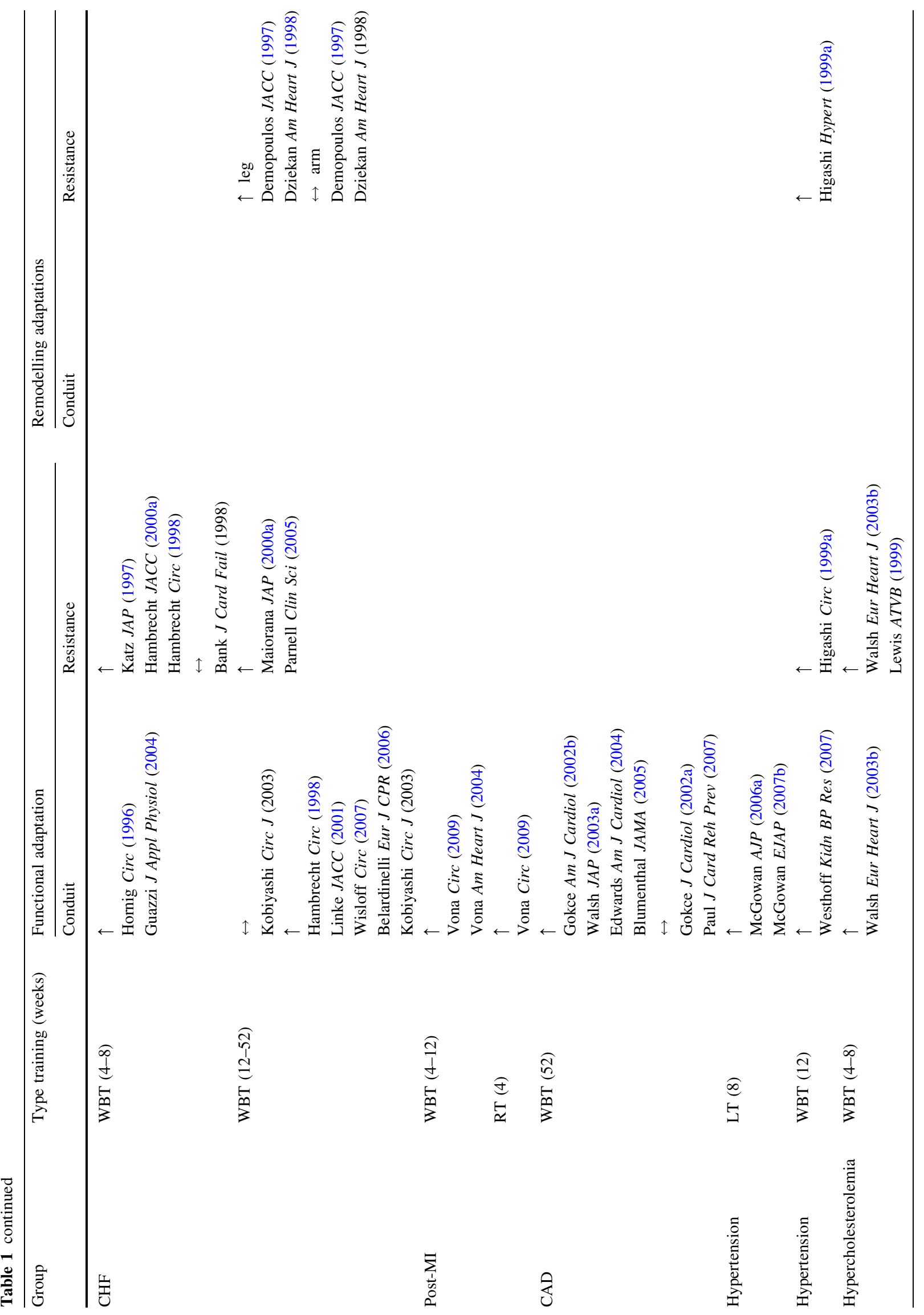




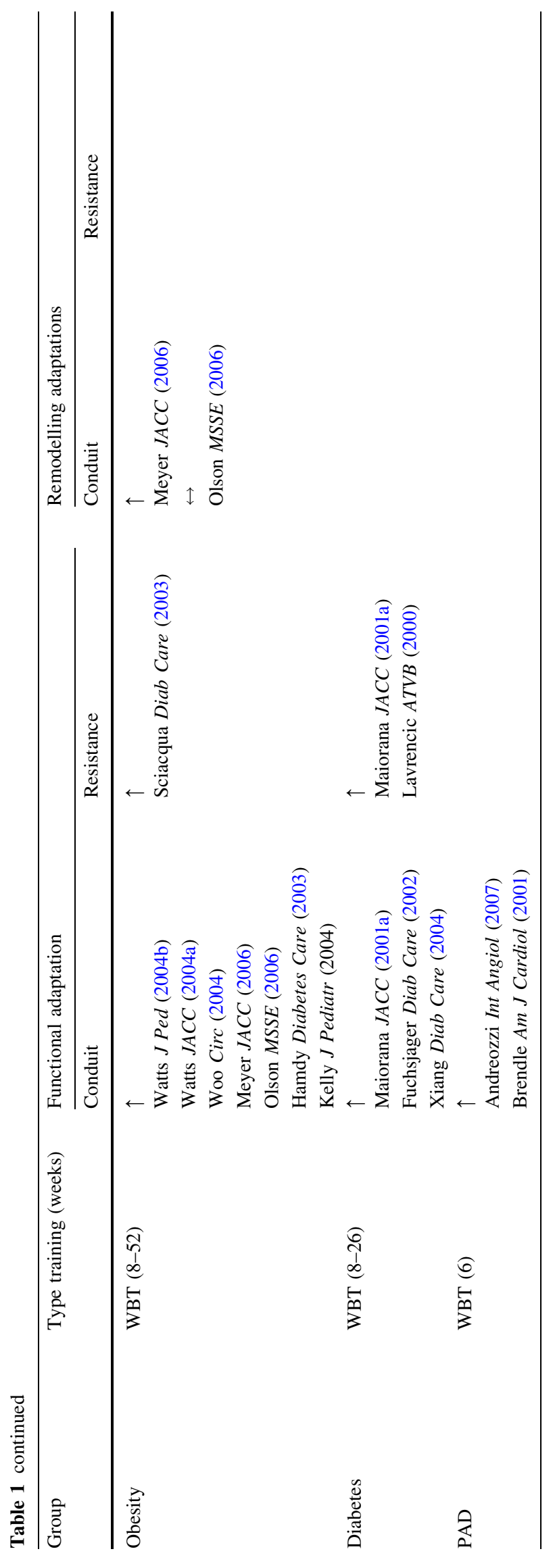

predisposition to atherogenic change (Goto et al. 2003; Green et al. 2008c; Wisloff et al. 2007).

Time-course of vascular adaptation to exercise

There have been few studies of the time-course of arterial functional or structural adaptation to exercise training in humans. However, 2-4 week training in rats increased endothelial NO synthesis in skeletal muscle arterioles and vasodilator responses to $\mathrm{ACh}$ and L-arginine. SNP responses were unaltered, suggesting enhanced endothelial function, but unchanged smooth muscle cell sensitivity to NO (Sun et al. 1994). A study of similar duration demonstrated augmented dilator response, which were partially abolished by L-NMMA infusion in rats (Koller et al. 1995). In another study, 4 weeks of training not only enhanced ACh-induced vasodilation of the rat aorta but also increased eNOS protein levels in aortic tissue (Delp and Laughlin 1997; Delp et al. 1993). Eight weeks of running in rabbits increased ACh reactivity in the aorta and pulmonary arteries, but not in the carotid artery (Chen and $\mathrm{Li}$ 1993), whilst 4 weeks of exercise in rats improved flowinduced dilation in skeletal muscle arteries, but not in mesenteric vessels (Sun et al. 1998). Improved endothelium-dependent vasodilation has been observed after as few as 7 days of endurance training in pigs in peripheral conduit vessels (McAllister and Laughlin 1997) as well as coronary conduit arteries (Laughlin et al. 2003a). These findings suggest that increased production of endothelial NO occurs rapidly in response to exercise training, particularly in arteries supplying active regions.

Studies performed over a longer duration have not consistently shown augmented endothelial function. Endothelium-dependent vasodilation was unaltered after 16-20 weeks of training in pigs (McAllister et al. 1996) and 16 weeks in rats (Kingwell et al. 1997a) (Laughlin 1995). There is also evidence that changes in eNOS expression are also time dependent. Expression of eNOS protein and enhanced ACh-mediated relaxation (Johnson et al. 2001) were evident after 1 week of training in pigs, whereas changes were not present after 16 weeks (Johnson and Laughlin 2000). These data suggest that long-term training is not consistently associated with enhanced vascular function. However, it should be borne in mind that prolonged exercise training enlarges arterial diameters in animals (Kramsch et al. 1981; Lash and Bohlen 1992; Leon and Bloor 1968; Wyatt and Mitchell 1978). As previously proposed (Laughlin 1995), it is conceivable that vascular remodelling, an endothelium and NO-dependent phenomenon (Gibbons and Dzau 1994; Kamiya and Togawa 1980; Langille and O'Donnell 1986; Prior et al. 2003; Rudic et al. 1998; Zarins et al. 1987), may partly supplant the need for acutely 
responsive vasodilator mechanisms to normalise shear stress during exercise bouts.

A time-dependent change in conduit and resistance artery endothelial function is found in the coronary circulation. Early animal studies indicated that training increased vasodilator responses in dogs (DiCarlo et al. 1989) and transport capacity in swine (Laughlin et al. 1989). Sessa et al. were the first to report that eNOS gene expression is enhanced by exercise training in the coronary arteries. They observed increased nitrite and NO production, and eNOS gene expression, following 10 days of training in dogs (Sessa et al. 1994). Exercise training also enhanced conduit artery NO-mediated dilation after 7-10 days of treadmill exercise training in another study of dogs (Wang et al. 1993). No changes were evident in response to SNP. Laughlin et al. (2003a) observed an improvement in conduit artery endothelial function in coronary arteries after 7 days of exercise training in pigs. In contrast, in the same study (Laughlin et al. 2003a), they did not demonstrate a change in resistance artery endothelial function after short-term exercise training. Interestingly, the same group also demonstrated that 16-20 week exercise training in pigs did not increase coronary conduit artery endothelial function (Laughlin 1995), while they demonstrated the presence of increased eNOS mRNA (Woodman et al. 1997) and increased bradykinin induced vasodilation (Muller et al. 1994) in coronary resistance vessels, suggesting that enhanced NO and endothelium-dependent dilation was persisting in these vessels. Finally, however, 16-22 weeks of training augmented vasodilator responses to adenosine in the large epicardial arteries of pigs, even after removal of the endothelium. This evidence suggests that changes in vasomotor response in coronary arteries with longer-term training might be due, at least in part, to adaptations within smooth muscle (Oltman et al. 1992). As recently reviewed by Laughlin et al., the animal data suggest that coronary arteries follow a time-dependent adaptation to exercise training, which is different between conduit and resistance arteries. Whilst smaller coronary arterioles exhibit enhanced endothelium dependent vasodilation after longer term training, larger coronary arteries adapt rapidly to training and then return towards baseline levels when exercise training continues (Laughlin et al. 2008).

In summary, animal studies suggest that short-term exercise training enhances eNOS and NO production and bioactivity, producing a short term buffer to the increased shear associated with exercise. After extended training, at least in the peripheral circulation, the increased production of NO and possibly other mediators induces structural changes in the vessels resulting in an increase in lumen diameter (Brown 2003; Prior et al. 2003). Shear stress may therefore be "structurally" normalised and endothelial NO activity returns towards initial levels.
Very little data exists regarding the time-course of arterial functional and structural adaptation to exercise training in humans. However, we recently completed a study in which measures of brachial and popliteal artery function and structure were collected every 2 weeks across an 8 week exercise training program in healthy young male subjects (Tinken et al. 2008). The results indicated that functional adaptation preceded changes in artery peak vasodilator capacity (Fig. 2). These findings support the notion that functional adaptations may be superseded by structural changes including artery remodelling may normalise shear stress. They confirm previous reports that endothelial function rapidly adapts to training and detraining (Haram et al. 2006; Pullin et al. 2004).

Healthy subjects versus subjects with cardiovascular disease

The detailed effects of exercise training in various populations with endothelial dysfunction are summarised in the Table 1 and fully reviewed elsewhere (Green et al. 2004; Maiorana et al. 2003). In subjects with cardiovascular risk factors and disease, exercise training of localised muscle groups (Hambrecht et al. 2000b; Hornig et al. 1996; Katz et al. 1997), and whole body exercise predominantly involving the lower limbs (Gielen et al. 2003; Gokce et al. 2002b; Hambrecht et al. 1998, 2000b, 2003; Higashi et al. 1999a; Linke et al. 2001; Maiorana et al. 2000a, 2001a; Schmidt et al. 2002; Walsh et al. 2003a, b), are associated with improvement in measures of $\mathrm{NO}$ vasodilator function. There is consistency in the literature pertaining to exercise training mediated improvement in vascular function in groups in whom it is initially depressed. In contrast, studies of healthy subjects, with presumably normal endothelial function, are less compelling (Bergholm et al. 1999; Clarkson et al. 1999; Franke et al. 1998; Green et al. 1994; Kingwell et al. 1997b; Maiorana et al. 2001b; Thijssen et al. 2007a) and improvement may be limited to older subjects or those who undertake greater volumes of training (Green et al. 2004; Maiorana et al. 2001b). Collectively, these findings suggest that subjects with impaired endothelial function may be more amenable to improvement in NO function as a result of training than healthy subjects.

Mechanisms responsible for change in vascular function and structure

\section{Vascular function}

Hambrecht et al. provided an insight into the mechanisms responsible for exercise-mediated improvements in endothelial function (Hambrecht et al. 2003). They studied the 
impact of the impact of 4 weeks of cycle exercise on the internal mammary artery of CAD subjects awaiting coronary artery bypass surgery. Training increased peak endothelium-dependent flow and flow-mediated dilation responses in the arteries of trained subjects, but not sedentary controls. After the final training session and the repeat in vivo vascular function assessments, a section of the internal mammary artery was harvested for in vitro vascular function assessment, immunohistochemistry, NO synthase mRNA isolation and protein quantification. Exercise training was associated with significantly higher NO synthase mRNA and protein expression and higher shear-stress related eNOS phosphorylation, which correlated with in vivo ACh-mediated vasodilator capacity. Exercise training therefore improves endothelial function in vivo by upregulating NO synthase protein expression and by increasing phosphorylation of this enzyme, effects consistent with a shear-stress mechanism for enhanced NO bioactivity with training.

Another explanation for improved vascular function with training was indirectly proposed by the results of Goto et al. (2003), who studied the effects of 12 weeks of exercise undertaken at low, moderate and high intensity and observed improvement in endothelial function in the moderate intensity group only. This occurred in the absence of changes in blood-borne measures of oxidative stress, whereas the high intensity group exhibited increased oxidative stress and no improvement in endothelial function. These findings suggest that the impact of exercise training on endothelial function may be dependent upon the intensity of exercise performed and the consequent balance between acute oxidative stress, chronic changes in antioxidant defences and their impact on NO bioavailability. Reactive oxygen species, such as superoxide anions, degrade NO before it has a vasodilator impact on vascular smooth muscle. However, repeated stimulation of NO production as a result of exercise training may reduce its degradation by free radicals (Fukai et al. 2000), directly decrease free radical production (Adams et al. 2005), or increase the expression of genes encoding for antioxidant enzymes (Ennezat et al. 2001).

\section{Vascular remodelling}

The classic study of Langille and O'Donnell established a link between changes in flow and arterial remodelling (Langille and O'Donnell 1986). They examined rabbit carotid arteries after unilateral ligation-mediated chronic decreases in flow (70\% reduction, 2 weeks). The diameter of the ligated vessel was significantly smaller than the contralateral control vessel and this change was dependent upon the endothelium, inferring that flow-mediated changes in vessel structure are dependent upon the release of a substance from endothelial cells. This concurred with a similar study which found that shear stress was autoregulated after initial perturbation by an arteriovenous fistula (Kamiya and Togawa 1980). Recent studies confirm that the stimulus to arterial remodelling is shear stress (Tuttle et al. 2001) and that vessels enlarge to regulate wall shear in NO-dependent manner (Tronc et al. 1996).

The above data are consistent with the evolving hypothesis that arterial shear stress is a homeostatically regulated variable (Vita et al. 2008). In this conceptual framework, shear stress mediated arterial enlargement, which is at least partly NO-dependent, acts to mitigate the increases in transmural pressure and wall stress brought about by repeated exercise bouts (Guyton and Hartley 1985; Langille et al. 1989; Lloyd et al. 2001; Prior et al. 2003; Tronc et al. 1996; Rodbard and Sarzana 1975; Zamir 1977). The consequent "structural" normalisation of shear may obviate the need for ongoing and acute functional adaptations (Green et al. 2004; Maiorana et al. 2003). One recent study in humans provides some support for this notion, as functional adaptations were superseded by apparent changes in artery size (Tinken et al. 2008).

\section{Optimal exercise training regimens}

Several studies raise the possibility that different modalities or intensities of exercise may impact upon the magnitude of vascular adaptation observed. Bergholm et al. reported that 3 months of high intensity running reduced endothelium-dependent function but not endotheliumindependent function (Bergholm et al. 1999). The degree of endothelial dysfunction following training was greatest in subjects with the largest improvements in $\dot{V} \mathrm{O}_{2 \max }$. The authors postulated that the training-induced decrease in circulating antioxidant levels may adversely affect endothelial function in the highly trained or overtrained state. Goto et al. (2003) studied the effects low $\left(25 \% \dot{V} \mathrm{O}_{2 \max }\right)$, moderate $\left(50 \% \dot{V} \mathrm{O}_{2 \max }\right)$ and high $\left(75 \% \dot{V} \mathrm{O}_{2 \max }\right)$ intensity training in young men. Endothelium-dependent forearm vasodilation improved in the moderate intensity group only. This occurred in the absence of changes in oxidative stress. In the high intensity group, endothelial function did not improve, but there was evidence for increased oxidative stress. Taken together, the findings of Bergholm and Goto suggest that low intensity exercise may fall below a given threshold for improvement in endothelial function, whilst moderate intensity exercise enhances NO bioavailability. Any improvement in vascular function resulting from highintensity exercise may be abrogated by excess oxidative stress. However, this hypothesis clearly requires further testing, as it is also evident that higher intensity training may enhance antioxidant defence against oxidative stress (Adams et al. 2005; Ennezat et al. 2001; Fukai et al. 2000). 
In terms of the impact of exercise modality on vascular adaptation, the majority of studies indicating improvement in vascular function have utilised aerobic, or large muscle group dynamic exercise modalities, such as walking, running or cycling (see Table 1). Some studies which have combined aerobic and weight resisted exercises have also demonstrated generalised improvements in vascular function (Maiorana et al. 2000b, 2001a; Walsh et al. 2003a, b; Watts et al. 2004a). Studies of resistance training have not observed changes in conduit artery function, but suggest that arterial remodelling may occur (Rakobowchuk et al. 2005). Importantly, recent studies suggest that different modes of exercise, even when performed at similar relative intensities, generate distinct patterns of blood flow and shear stress through active and inactive vessel beds, raising the possibility of different shear mediated signals for adaptation (Thijssen et al. 2009). Differences in blood pressure and transmural pressure between exercise modes may also contribute to differences in the adaptations evident (Laughlin et al. 2008). Recent studies also suggest differences in endothelial adaptations to exercise of differing modalities in heart failure and healthy subjects (Schjerve et al. 2008; Wisloff et al. 2007).

\section{Summary: Exercise training and vascular adaptation}

Collectively, the above data from both animal and human studies of exercise training suggest that functional and structural adaptations of the vasculature to exercise training alter with training duration and intensity and the vessel beds involved. Exercise training is associated with significant reductions in primary (Hakim et al. 1999; Myers et al. 2002; Sesso et al. 2000) and secondary vascular events (Jolliffe et al. 2001). The effects of exercise on cardiovascular risk factors do not account for the magnitude of risk reduction (Green et al. 2008c; Mora et al. 2007). Exercise exerts direct effects on the vasculature by virtue of the impact of repetitive intermittent increases in shear stress on the vascular endothelium, which responds by transducing functional and structural vascular adaptations which ultimately decrease atherosclerotic risk. Changes in transmural wall pressure may also represent a signal for chronic adaptation (Laughlin et al. 2008). Hence, exerciseinduced improvements in vessel wall function and structure represent a "vascular conditioning" effect, which provides a plausible mechanistic explanation for the cardioprotective benefits of exercise, independent of the impact of exercise on traditional $\mathrm{CV}$ risk factors.

The clinical relevance of the vascular adaptations to exercise training was recently highlighted in a study which compared the effects of percutaneous coronary intervention with stenting $(\mathrm{PCI})$ to exercise training alone in 101 male subjects (Hambrecht et al. 2004). After 12 months follow- up, the PCI group exhibited significantly increased lumen diameter $(0.53-2.57 \mathrm{~mm})$ and decreased relative stenosis diameter (80.7-11.8\%), whereas exercise training had no impact on stenotic characteristics $(0.66-0.69 \mathrm{~mm}, 77.9$ $76.5 \%$ ). Despite this, there was significantly higher eventfree survival in the exercise training group (88 vs. $70 \%$ ). This study reinforces the fact that coronary intervention treats a short segment of the diseased coronary tree, whilst exercise training exerts beneficial effects on endothelial function and disease progression in the entire arterial bed. The authors concluded that, in contrast to exercise training, interventional cardiology represents a palliative care measure with respect to the underlying atherosclerotic disease process and that exercise training should be a cornerstone of primary and secondary prevention efforts.

\section{Summary}

Physical inactivity is considered a risk factor for cardiovascular disease in humans and exercise training is associated with a decrease in risk which is similar in magnitude ( $\sim 30 \%)$ to that associated with pharmacological strategies. However, the effects of inactivity and exercise training on established and novel cardiovascular risk factors are relatively modest and cannot fully account for the impact of inactivity and exercise on vascular risk. However, both inactivity and exercise have direct effects on the vasculature and specific mechanistic pathways, for example those associated with shear stress and pulse pressure, have been identified which provide a basis for direct vascular conditioning and deconditioning effects of exercise and inactivity, respectively.

Inactivity is associated with rapid changes in arterial structure which result in inward remodelling. Vasodilator function in the remodelled resistance and conduit arteries appears to be within the normal range. It is possible that studies have not observed changes in vasodilator function because structural changes occur rapidly and allow for normalisation of function (Fig. 2). Some evidence exists for enhanced and persistent increases in vasoconstrictor activity as a result of inactivity, even after artery remodeling has occurred.

Exercise training is typically associated with enhanced vasodilator activity which is ultimately superseded by outwards arterial remodelling and consequent re-normalisation of dilator function. These effects occur in vasculature of the active muscle beds, but also seem to be generalised to arteries supplying skeletal muscle that is not directly involved in the training stimulus. Shear stress on the artery wall appears to be a variable which is regulated by changes in vasodilator function in the first instance, and ultimately adaptive changes in artery size as the exercise 
stimulus persists. There is less evidence, in either conduit or resistance vessels, for diminished vasoconstrictor tone or function as an adaptation to training.

By far the majority of research has been undertaken on the relatively accessible and easily studied peripheral skeletal muscle conduit and resistance arteries. However, the limited extant evidence regarding coronary vascular adaptations suggests that the impact of exercise is consistent between the skeletal muscle and coronary circulations. Surprisingly, given the established epidemiological evidence linking inactivity and cardiovascular risk, there appear to be no studies which have directly assessed the impact of inactivity on coronary artery structure or function in humans.

Studies on the time-course of change in artery structure and function in response to inactivity and exercise are in their infancy in humans, but the limited available evidence supports the notion that functional change precedes that in structure and that both can occur rapidly across a timecourse of days and weeks, rather than months or years. The relative impacts of different durations or models of inactivity, or different exercise volumes and intensities, has not been comprehensively studied to date.

In conclusion, inactivity and exercise have direct "vascular deconditioning and conditioning" effects which likely modify cardiovascular risk. However, the nature and impact of inactivity and exercise on vascular structure and function suggest that inactivity and exercise are not simply the opposite ends of a linear spectrum of physiological adaptation.

Acknowledgments DHJT is supported by The Netherlands Organization for Scientific Research (NWO-grant 82507010). DJG and AJM are supported by the National Heart Foundation of Australia and DJG receives funding from the Australian Research Council.

Open Access This article is distributed under the terms of the Creative Commons Attribution Noncommercial License which permits any noncommercial use, distribution, and reproduction in any medium, provided the original author(s) and source are credited.

\section{References}

Adams V, Linke A, Krankel N, Erbs S, Gielen S, Mobius-Winkler S, Gummert JF, Mohr FW, Schuler G, Hambrecht R (2005) Impact of regular physical activity on the $\mathrm{NAD}(\mathrm{P}) \mathrm{H}$ oxidase and angiotensin receptor system in patients with coronary artery disease. Circulation 111:555-562

Allen JD, Geaghan JP, Greenway F, Welsch MA (2003) Time course of improved flow-mediated dilation after short-term exercise training. MSSE 35:847-853

Andersen P, Henriksson J (1977) Capillary supply of the quadriceps femoris muscle of man: adaptive response to exercise. J Physiol 270:677-690

Andreozzi GM, Leone A, Laudani R, Deinite G, Martini R (2007) Acute impairment of the endothelial function by maximal treadmill exercise in patients with intermittent claudication, and its improvement after supervised physical training. Int Angiol 26:12-17

Bank AJ, Shammas RA, Mullen K, Chuang PP (1998) Effects of short-term forearm exercise training on resistance vessel endothelial function in normal subjects and patients with heart failure. J Card Fail 4:193-201

Bauman WA, Spungen AM, Raza M, Rothstein J, Zhang RL, Zhong YG, Tsuruta M, Shahidi R, Pierson RN Jr, Wang J et al (1992) Coronary artery disease: metabolic risk factors and latent disease in individuals with paraplegia. Mt Sinai J Med NY 59:163-168

Belardinelli R, Capestro F, Misiani A, Scipione P, Georgiou D (2006) Moderate exercise training improves functional capacity, quality of life, and endothelium-dependent vasodilation in chronic heart failure patients with implantable cardioverter defibrillators and cardiac resynchronization therapy. Eur J Cardiovasc Prev Rehabil 13:818-825

Ben Driss A, Benessiano J, Poitevin P, Levy BI, Michel JB (1997) Arterial expansive remodeling induced by high flow rates. Am J Physiol 272:H851-858

Berdeaux A, Ghaleh B, Dubois-Rande JL, Vigue B, Drieu La Rochelle C, Hittinger L, Giudicelli JF (1994) Role of vascular endothelium in exercise-induced dilation of large epicardial coronary arteries in conscious dogs. Circulation 89:2799-2808

Berg HE, Tesch PA (1996) Changes in muscle function in response to 10 days of lower limb unloading in humans. Acta Physiol Scand 157:63-70

Bergholm R, Makimattila S, Valkonen M, Liu ML, Lahdenpera S, Taskinen MR, Sovijarvi A, Malmberg P, Yki-Jarvinen H (1999) Intense physical training decreases circulating antioxidants and endothelium-dependent vasodilatation in vivo. Atherosclerosis 145:341-349

Billman GE, Kukielka M (2006) Effect of endurance exercise training on heart rate onset and heart rate recovery responses to exercise in animals susceptible to ventricular fibrillation. J Appl Physiol 102(1):231-240

Black MA, Cable NT, Thijssen DH, Green DJ (2008a) Importance of measuring the time course of flow-mediated dilatation in humans. Hypertension 51:203-210

Black MA, Green DJ, Cable NT (2008b) Exercise prevents agerelated decline in nitric-oxide-mediated vasodilator function in cutaneous microvessels. J Physiol 586(14):3511-3524

Blair SN, Kohl HW 3rd, Barlow CE, Paffenbarger RS Jr, Gibbons LW, Macera CA (1995) Changes in physical fitness and allcause mortality. A prospective study of healthy and unhealthy men. JAMA 273:1093-1098

Blair SN, Kampert JB, Kohl HW 3rd, Barlow CE, Macera CA, Paffenbarger RS Jr, Gibbons LW (1996) Influences of cardiorespiratory fitness and other precursors on cardiovascular disease and all-cause mortality in men and women. JAMA 276:205-210

Bleeker MW, Hopman MT, Rongen GA, Smits P (2004) Unilateral lower limb suspension can cause deep venous thrombosis. Am J Physiol 286:R1176-R1177

Bleeker MW, De Groot PC, Poelkens F, Rongen GA, Smits P, Hopman MT (2005a) Vascular adaptation to 4 wk of deconditioning by unilateral lower limb suspension. Am J Physiol Heart Circ Physiol 288:H1747-1755

Bleeker MW, Kooijman M, Rongen GA, Hopman MT, Smits P (2005b) Preserved contribution of nitric oxide to baseline vascular tone in deconditioned human skeletal muscle. J Physiol 565:685-694

Bleeker MW, De Groot PC, Rongen GA, Rittweger J, Felsenberg D, Smits P, Hopman MT (2005c) Vascular adaptation to deconditioning and the effect of an exercise countermeasure: results of the Berlin Bed Rest study. J Appl Physiol 99(4):1293-1300

Blumenthal JA, Sherwood A, Babyak MA, Watkins LL, Waugh R, Georgiades A, Bacon SL, Hayano J, Coleman RE, Hinderliter A 
(2005) Effects of exercise and stress management training on markers of cardiovascular risk in patients with ischemic heart disease: A randomized controlled trial. JAMA 293:1626-1634

Bonnin P, Ben Driss A, Benessiano J, Maillet A, Pavy le Traon A, Levy BI (2001) Enhanced flow-dependent vasodilatation after bed rest, a possible mechanism for orthostatic intolerance in humans. Eur J Appl Physiol 85:420-426

Booth FW, Chakravarthy MV, Spangenburg EE (2002) Exercise and gene expression: physiological regulation of the human genome through physical activity. J Physiol 543:399-411

Brendle DC, Joseph LJO, Corretti MC, Gardner AW, Katzel LI (2001) Effects of exercise rehabilitation on endothelial reactivity in older patients with peripheral arterial disease. Am J Cardiol 87:324-329

Brown MD (2003) Exercise and coronary vascular remodelling in the healthy heart. Exp Physiol 88:645-658

Brown MD, Cotter MA, Hudlicka O, Vrbova G (1976) The effects of different patterns of muscle activity on capillary density, mechanical properties and structure of slow and fast rabbit muscles. Pflugers Arch 361:241-250

Buchheit M, Simon C, Charloux A, Doutreleau S, Piquard F, Brandenberger G (2005) Heart rate variability and intensity of habitual physical activity in middle-aged persons. Med Sci Sports Exerc 37:1530-1534

Cardus D, Ribas-Cardus F, McTaggart WG (1992) Coronary risk in spinal cord injury: assessment following a multivariate approach. Arch Phys Med Rehabil 73:930-933

Celermajer DS, Sorensen KE, Gooch VM, Spiegelhalter DJ, Miller OI, Sullivan ID, Lloyd JK, Deanfield JE (1992) Non-invasive detection of endothelial dysfunction in children and adults at risk of atherosclerosis. Lancet 340:1111-1115

Chen HI, Li HT (1993) Physical conditioning can modulate endothelium-dependent vasorelaxation in rabbits. Arterioscler Thromb 13:852-856

Christ F, Gamble J, Baranov V, Kotov A, Chouker A, Thiel M, Gartside IB, Moser CM, Abicht J, Messmer K (2001) Changes in microvascular fluid filtration capacity during 120 days of 6 degrees head-down tilt. J Appl Physiol 91:2517-2522

Clarkson P, Montgomery HE, Mullen MJ, Donald AE, Powe AJ, Bull T, Jubb M, World M, Deanfield JE (1999) Exercise training enhances endothelial function in young men. J Am Coll Cardiol 33:1379-1385

Clausen JP, Klausen K, Rasmussen B, Trap-Jensen J (1973) Central and peripheral circulatory changes after training of the arms or legs. Am J Physiol 225:675-682

Convertino VA, Doerr DF, Stein SL (1989) Changes in size and compliance of the calf after 30 days of simulated microgravity. $\mathbf{J}$ Appl Physiol 66:1509-1512

Convertino VA, Tripp LD, Ludwig DA, Duff J, Chelette TL (1998) Female exposure to high G: chronic adaptations of cardiovascular functions. Aviat Space Environ Med 69:875-882

Conway J (1963) A vascular abnormality in hypertension. A study of blood flow in the forearm. Circulation 27:520-529

Currens JH, White PD (1961) Half a century of running. Clinical, physiologic and autopsy findings in the case of Clarence DeMar ("Mr. Marathon"). N Engl J Med 265:988-993

Davy KP, DeSouza CA, Jones PP, Seals DR (1998) Elevated heart rate variability in physically active young and older adult women. Clin Sci 94:579-584

De Groot PC, Van Kuppevelt DH, Pons C, Snoek G, Van Der Woude LH, Hopman MT (2003) Time course of arterial vascular adaptations to inactivity and paralyses in humans. Med Sci Sports Exerc 35:1977-1985

de Groot PC, Poelkens F, Kooijman M, Hopman MT (2004) Preserved flow-mediated dilation in the inactive legs of spinal cord-injured individuals. Am J Physiol Heart Circ Physiol 287:H374-380

de Groot P, Crozier J, Rakobowchuk M, Hopman M, MacDonald M (2005) Electrical stimulation alters FMD and arterial compliance in extremely inactive legs. Med Sci Sports Exerc 37:1356-1364

de Groot PC, Bleeker MW, Hopman MT (2006a) Magnitude and time course of arterial vascular adaptations to inactivity in humans. Exerc Sport Sci Rev 34:65-71

de Groot PC, Bleeker MW, van Kuppevelt DH, van der Woude LH, Hopman MT (2006b) Rapid and extensive arterial adaptations after spinal cord injury. Arch Phys Med Rehabil 87:688-696

Dekker JM, Schouten EG, Klootwijk P, Pool J, Swenne CA, Kromhout D (1997) Heart rate variability from short electrocardiographic recordings predicts mortality from all causes in middle-aged and elderly men. The Zutphen Study. Am J Epidemiol 145:899-908

Delp MD, Laughlin MH (1997) Time course of enhanced endothelium-mediated dilation in aorta of trained rats. Med Sci Sports Exerc 29:1454-1461

Delp MD, McAllister RM, Laughlin MH (1993) Exercise training alters endothelium-dependent vasoreactivity of rat abdominal aorta. J Appl Physiol 75:1354-1363

Demiot C, Dignat-George F, Fortrat JO, Sabatier F, Gharib C, Larina I, Gauquelin-Koch G, Hughson R, Custaud MA (2007) WISE 2005: chronic bed rest impairs microcirculatory endothelium in women. Am J Physiol Heart Circ Physiol 293:H3159-3164

Demopoulos L, Bijou R, Fergus I, Jones M, Strom J, LeJemtel TH (1997) Exercise training in patients with severe congestive heart failure: enhancing peak aerobic capacity while minimizing the increase in ventricular wall stress. J Am Coll Cardiol 29:597603

DeSouza CA, Shapiro LF, Clevenger CM, Dinenno FA, Monahan KD, Tanaka H, Seals DR (2000) Regular aerobic exercise prevents and restores age-related declines in endotheliumdependent vasodilation in healthy men. Circulation 102:13511357

DiCarlo SE, Blair RW, Bishop VS, Stone HL (1989) Daily exercise enhances coronary resistance vessel sensitivity to pharmacological activation. J Appl Physiol 66:421-428

Dimmeler S, Zeiher AM (2003) Exercise and cardiovascular health: get active to "AKTivate" your endothelial nitric oxide synthase. Circulation 107:3118-3120

Dinenno FA, Tanaka H, Monahan KD, Clevenger CM, Eskurza I, DeSouza CA, Seals DR (2001) Regular endurance exercise induces expansive arterial remodelling in the trained limbs of healthy men. J Physiol 534:287-295

Doshi SN, Naka KK, Payne N, Jones CJ, Ashton M, Lewis MJ, Goodfellow J (2001) Flow-mediated dilatation following wrist and upper arm occlusion in humans: the contribution of nitric oxide. Clin Sci Lond 101:629-635

Duffy SJ, Castle SF, Harper RW, Meredith IT (1999) Contribution of vasodilator prostanoids and nitric oxide to resting flow, metabolic vasodilation, and flow-mediated dilation in human coronary circulation. Circulation 100:1951-1957

Dziekan G, Myers J, Goebbels U, Muller P, Reinhart W, Ratti R, Hafeli W, Dubach P (1998) Effects of exercise training on limb blood flow in patients with reduced ventricular function. Am Heart J 136:22-30

Ebrahim S, Beswick A, Burke M, Davey Smith G (2006) Multiple risk factor interventions for primary prevention of coronary heart disease. Cochrane Database Syst Rev (4):CD001561

Edwards DG, Schofield RS, Lennon SL, Pierce GL, Nichols WW, Braith RW (2004) Effect of exercise training on endothelial function in men with coronary artery disease. Am J Cardiol 93:617-620 
Eisenach JH, Clark ES, Charkoudian N, Dinenno FA, Atkinson JL, Fealey RD, Dietz NM, Joyner MJ (2002) Effects of chronic sympathectomy on vascular function in the human forearm. J Appl Physiol 92:2019-2025

Ennezat PV, Malendowicz SL, Testa M, Colombo PC, Cohen-Solal A, Evans T, LeJemtel TH (2001) Physical training in patients with chronic heart failure enhances the expression of genes encoding antioxidative enzymes. J Am Coll Cardiol 38:194-198

Folkow B (1978) The fourth Volhard lecture: cardiovascular structural adaptation; its role in the initiation and maintenance of primary hypertension. Clin Sci Mol Med Suppl 4:3s-22s

Folkow B, Grimby G, Thulesius O (1955) Adaptive structural changes in the vascular walls in hypertension and their relation to the control of peripheral resistance. Acta Physiol Scand $44: 255$

Folkow B, Grimby G, Thulesius O (1958) Adaptive structural changes of the vascular walls in hypertension and their relation to the control of the peripheral resistance. Acta Physiol Scand 44:255-272

Franke WD, Stephens GM, Schmid PG 3rd (1998) Effects of intense exercise training on endothelium-dependent exercise-induced vasodilatation. Clin Physiol 18:521-528

Fuchsjager-Mayrl G, Pleiner J, Wiesinger GF, Sieder AE, Quittan M, Nuhr MJ, Francesconi C, Seit HP, Francesconi M, Schmetterer L, Wolzt M (2002) Exercise training improves vascular endothelial function in patients with type 1 diabetes. Diabetes Care 25:1795-1801

Fukai T, Siegfried MR, Ushio-Fukai M, Cheng Y, Kojda G, Harrison DG (2000) Regulation of the vascular extracellular superoxide dismutase by nitric oxide and exercise training. J Clin Invest 105:1631-1639

Galbo H (1983) Hormonal and metabolic adaptation to exercise. Thieme-Stratton, New York

Gamrin L, Berg HE, Essen P, Tesch PA, Hultman E, Garlick PJ, McNurlan MA, Wernerman J (1998) The effect of unloading on protein synthesis in human skeletal muscle. Acta Physiol Scand 163:369-377

Ganz P, Vita JA (2003) Testing endothelial vasomotor function: nitric oxide, a multipotent molecule. Circulation 108:2049-2053

Garshick E, Kelley A, Cohen SA, Garrison A, Tun CG, Gagnon D, Brown R (2005) A prospective assessment of mortality in chronic spinal cord injury. Spinal Cord 43:408-416

Gerritsen J, Dekker JM, Ten Voorde BJ, Kostense PJ, Heine RJ, Bouter LM, Heethaar RM, Stehouwer CDA (2002) Impaired autonomic function is associated with increased mortality, especially in subjects with diabetes, hypertension, or a history of cardiovascular disease. Diabetes Care 24:1793-1798

Gibbons GH, Dzau VJ (1994) The emerging concept of vascular remodeling. N Engl J Med 330:1431-1438

Gielen S, Erbs S, Linke A, Mobius-Winkler S, Schuler G, Hambrecht R (2003) Home-based versus hospital-based exercise programs in patients with coronary artery disease: effects on coronary vasomotion. Am Heart J 145:E3

Gleser MA (1973) Effects of hypoxia and physical training on hemodynamic adjustments to one-legged exercise. J Appl Physiol 34:655-659

Gokce N, Keaney JF Jr, Hunter LM, Watkins MT, Menzoian JO, Vita JA (2002a) Risk stratification for postoperative cardiovascular events via noninvasive assessment of endothelial function: a prospective study. Circulation 105:1567-1572

Gokce N, Vita JA, Bader DS, Sherman DL, Hunter LM, Holbrook M, O'Malley C, Keaney JF Jr, Balady GJ (2002b) Effect of exercise on upper and lower extremity endothelial function in patients with coronary artery disease. Am J Cardiol 90:124-127

Goto C, Higashi Y, Kimura M, Noma K, Hara K, Nakagawa K, Kawamura M, Chayama K, Yoshizumi M, Nara I (2003) Effect of different intensities of exercise on endothelium-dependent vasodilation in humans: role of endothelium-dependent nitric oxide and oxidative stress. Circulation 108:530-535

Green DJ, Cable NT, Fox C, Rankin JM, Taylor RR (1994) Modification of forearm resistance vessels by exercise training in young men. J Appl Physiol 77:1829-1833

Green DJ, Fowler DT, O'Driscoll JG, Blanksby BA, Taylor RR (1996) Endothelium-derived nitric oxide activity in forearm vessels of tennis players. J Appl Physiol 81:943-948

Green DJ, O'Driscoll JG, Blanksby BA, Taylor RR (1997) Effect of casting on forearm resistance vessels in young men. Med Sci Sports Exerc 29:1325-1331

Green D, Cheetham C, Mavaddat L, Watts K, Best M, Taylor R, O'Driscoll G (2002a) Effect of lower limb exercise on forearm vascular function: contribution of nitric oxide. Am J Physiol Heart Circ Physiol 283:H899-907

Green D, Cheetham C, Reed C, Dembo L, O’Driscoll G (2002b) Assessment of brachial artery blood flow across the cardiac cycle: retrograde flows during cycle ergometry. J Appl Physiol 93:361-368

Green DJ, Walsh JH, Maiorana A, Best MJ, Taylor RR, O'Driscoll JG (2003) Exercise-induced improvement in endothelial dysfunction is not mediated by changes in $\mathrm{CV}$ risk factors: pooled analysis of diverse patient populations. Am J Physiol Heart Circ Physiol 285:H2679-2687

Green DJ, Maiorana A, O'Driscoll G, Taylor R (2004) Effect of exercise training on endothelium-derived nitric oxide function in humans. J Physiol 561:1-25

Green DJ, Bilsborough W, Naylor LH, Reed C, Wright J, O’Driscoll G, Walsh JH (2005) Comparison of forearm blood flow responses to incremental handgrip and cycle ergometer exercise: relative contribution of nitric oxide. J Physiol 562:617-628

Green DJ, Maiorana AJ, Cable NT (2008a) Exercise training does induce vascular adaptations beyond the active muscle beds. $\mathrm{J}$ Appl Physiol 105:1002-1004

Green DJ, Naylor LH, George K, Dempsey JA, Stickland MK, Katayama K (2008b) Cardiovascular and pulmonay adaptations to exercise training. In: Taylor NAS, Groeller H, McLennan PL (eds) Physiological bases of human performance during work and exercise. Churchill Livingstone, Oxford

Green DJ, O'Driscoll G, Joyner MJ, Cable NT (2008c) Exercise and cardiovascular risk reduction: time to update the rationale for exercise? J Appl Physiol 105(2):766-768

Groah SL, Weitzenkamp D, Sett P, Soni B, Savic G (2001) The relationship between neurological level of injury and symptomatic cardiovascular disease risk in the aging spinal injured. Spinal Cord 39:310-317

Guazzi M, Reina G, Tumminello G, Guazzi MD (2004) Improvement of alveolar-capillary membrane diffusing capacity with exercise training in chronic heart failure. J Appl Physiol 97:1866-1873

Guyton JR, Hartley CJ (1985) Flow restriction of one carotid artery in juvenile rats inhibits growth of arterial diameter. Am J Physiol 248:H540-546

Hakim AA, Curb JD, Petrovitch H, Rodriguez BL, Yano K, Ross GW, White LR, Abbott RD (1999) Effects of walking on coronary heart disease in elderly men: the Honolulu heart program. Circulation 100:9-13

Hambrecht R, Fiehn E, Weigl C, Gielen S, Hamann C, Kaiser R, Yu J, Adams V, Niebauer J, Schuler G (1998) Regular physical exercise corrects endothelial dysfunction and improves exercise capacity in patients with chronic heart failure. Circulation 98:2709-2715

Hambrecht R, Hilbrich L, Erbs S, Gielen S, Fiehn E, Schoene N, Schuler G (2000a) Correction of endothelial dysfunction in chronic heart failure: additional effects of exercise training and oral L-arginine supplementation. J Am Coll Cardiol 35:706-713 
Hambrecht R, Wolf A, Gielen S, Linke A, Hofer J, Erbs S, Schoene N, Schuler G (2000b) Effect of exercise on coronary endothelial function in patients with coronary artery disease. N Engl J Med 342:454-460

Hambrecht R, Adams V, Erbs S, Linke A, Krankel N, Shu Y, Baither Y, Gielen S, Thiele H, Gummert JF, Mohr FW, Schuler G (2003) Regular physical activity improves endothelial function in patients with coronary artery disease by increasing phosphorylation of endothelial nitric oxide synthase. Circulation 107:31523158

Hambrecht R, Walther C, Mobius-Winkler S, Gielen S, Linke A, Conradi K, Erbs S, Kluge R, Kendziorra K, Sabri O, Sick P, Schuler G (2004) Percutaneous coronary angioplasty compared with exercise training in patients with stable coronary artery disease: a randomized trial. Circulation 109:1371-1378

Hamburg NM, McMackin CJ, Huang AL, Shenouda SM, Widlansky ME, Schulz E, Gokce N, Ruderman NB, Keaney JF Jr, Vita JA (2007) Physical inactivity rapidly induces insulin resistance and microvascular dysfunction in healthy volunteers. Arterioscler Thromb Vasc Biol 27:2650-2656

Hamdy O, Ledbury S, Mullooly C, Jarema C, Porter S, Ovalle K, Moussa A, Caselli A, Caballero AE, Economides PA, Veves A, Horton ES (2003) Lifestyle modification improves endothelial function in obese subjects with the insulin resistance syndrome. Diabetes Care 26:2119-2125

Haram PM, Adams V, Kemi OJ, Brubakk AO, Hambrecht R, Ellingsen O, Wisloff U (2006) Time-course of endothelial adaptation following acute and regular exercise. Eur J Cardiovasc Prev Rehabil 13:585-591

Hardie KL, Kinlay S, Hardy DB, Wlodarczyk J, Silberberg JS, Fletcher PJ (1997) Reproducibility of brachial ultrasonography and flow-mediated dilatation (FMD) for assessing endothelial function. Aust NZ J Med 27:649-652

Hashmonai M, Kopelman D (2003) History of sympathetic surgery. Clin Auton Res 13(Suppl 1):I6-9

Haskell WL, Sims C, Myll J, Bortz WM, St Goar FG, Alderman EL (1993) Coronary artery size and dilating capacity in ultradistance runners. Circulation 87:1076-1082

Hesse C, Siedler H, Luntz SP, Arendt BM, Goerlich R, Fricker R, Heer M, Haefeli WE (2005) Modulation of endothelial and smooth muscle function by bed rest and hypoenergetic, low-fat nutrition. J Appl Physiol 99:2196-2203

Higashi Y, Oshima T, Ozono R, Matsuura H, Kajiyama G (1997) Aging and severity of hypertension attenuate endotheliumdependent renal vascular relaxation in humans. Hypertension 30:252-258

Higashi Y, Sasaki S, Kurisu S, Yoshimizu A, Sasaki N, Matsuura H, Kajiyama G, Oshima T (1999a) Regular aerobic exercise augments endothelium-dependent vascular relaxation in normotensive as well as hypertensive subjects: role of endotheliumderived nitric oxide. Circulation 100:1194-1202

Higashi Y, Sasaki S, Sasaki N, Nakagawa K, Ueda T, Yoshimizu A, Kurisu S, Matsuura H, Kajiyama G, Oshima T (1999b) Daily aerobic exercise improves reactive hyperemia in patients with essential hypertension. Hypertension 33:591-597

Hildick-Smith DJ, Johnson PJ, Wisbey CR, Winter EM, Shapiro LM (2000) Coronary flow reserve is supranormal in endurance athletes: an adenosine transthoracic echocardiographic study. Heart 84:383-389

Hoelting BD, Scheuermann BW, Barstow TJ (2001) Effect of contraction frequency on leg blood flow during knee extension exercise in humans. J Appl Physiol 91:671-679

Hopman MT, Groothuis JT, Flendrie M, Gerrits KH, Houtman S (2002) Increased vascular resistance in paralyzed legs after spinal cord injury is reversible by training. J Appl Physiol 93:1966-1972
Hornig B, Maier V, Drexler H (1996) Physical training improves endothelial function in patients with chronic heart failure. Circulation 93:210-214

Hudlicka O, Brown M, Cotter M, Smith M, Vrbova G (1977) The effect of long-term stimulation of fast muscles on their blood flow, metabolism and ability to withstand fatigue. Pflugers Arch 369:141-149

Hughson RL, Shoemaker JK, Tschakovsky ME, Kowalchuk JM (1996) Dependence of muscle $V_{2}$ on blood flow dynamics at onset of forearm exercise. J Appl Physiol 81:1619-1626

Hunt BE, Farquhar WB, Taylor JA (2001) Does reduced vascular stiffening fully explain preserved cardiovagal baroreflex function in older, physically active men? Circulation 103:2424-2427

Huonker M, Halle M, Keul J (1996) Structural and functional adaptations of the cardiovascular system by training. Int J Sports Med 17(Suppl 3):S164-172

Huonker M, Schmid A, Schmidt-Trucksass A, Grathwohl D, Keul J (2003) Size and blood flow of central and peripheral arteries in highly trained able-bodied and disabled athletes. J Appl Physiol 95:685-691

Imai K, Kadowaki T, Aizawa Y (2004) Standardized indices of mortality among persons with spinal cord injury: accelerated aging process. Ind Health 42:213-218

Jasperse JL, Laughlin MH (2006) Endothelial function and exercise training: evidence from studies using animal models. Med Sci Sports Exerc 38:445-454

Joannides R, Haefeli WE, Linder L, Richard V, Bakkali EH, Thuillez C, Luscher TF (1995) Nitric oxide is responsible for flowdependent dilatation of human peripheral conduit arteries in vivo. Circulation 91:1314-1319

Johnson LR, Laughlin MH (2000) Chronic exercise training does not alter pulmonary vasorelaxation in normal pigs. J Appl Physiol 88:2008-2014

Johnson LR, Rush JW, Turk JR, Price EM, Laughlin MH (2001) Short-term exercise training increases ACh-induced relaxation and eNOS protein in porcine pulmonary arteries. J Appl Physiol 90:1102-1110

Jolliffe JA, Rees K, Taylor RS, Thompson D, Oldridge N, Ebrahim S (2001) Exercise-based rehabilitation for coronary heart disease. Cochrane Database Syst Rev: CD001800

Jones AW, Rubin LJ, Magliola L (1999) Endothelin-1 sensitivity of porcine coronary arteries is reduced by exercise training and is gender dependent. J Appl Physiol 87:1172-1177

Joyner MJ, Dietz NM, Shepherd JT (2001) From Belfast to Mayo and beyond: the use and future of plethysmography to study blood flow in human limbs. J Appl Physiol 91:2431-2441

Kamiya A, Togawa T (1980) Adaptive regulation of wall shear stress to flow change in the canine carotid artery. Am J Physiol 239:H14-21

Kassab GS, Rider CA, Tang NJ, Fung YC (1993) Morphometry of pig coronary arterial trees. Am J Physiol 265:H350-365

Katz SD, Yuen J, Bijou R, LeJemtel TH (1997) Training improves endothelium-dependent vasodilation in resistance vessels of patients with heart failure. J Appl Physiol 82:1488-1492

Kingwell BA, Arnold PJ, Jennings GL, Dart AM (1997a) Spontaneous running increases aortic compliance in Wistar-Kyoto rats. Cardiovasc Res 35:132-137

Kingwell BA, Sherrard B, Jennings GL, Dart AM (1997b) Four weeks of cycle training increases basal production of nitric oxide from the forearm. Am J Physiol 272:H1070-1077

Klausen K, Secher NH, Clausen JP, Hartling O, Trap-Jensen J (1982) Central and regional circulatory adaptations to one-leg training. J Appl Physiol 52:976-983

Kobayashi N, Tsuruya Y, Iwasawa T, Ikeda N, Hashimoto S, Yasu T, Ueba H, Kubo N, Fujii M, Kawakami M, Saito M (2003) Exercise training in patients with chronic heart failure improves 
endothelial function predominantly in the trained extremities. Circ J 67

Koller A, Huang A, Sun D, Kaley G (1995) Exercise training augments flow-dependent dilation in rat skeletal muscle arterioles. Role of endothelial nitric oxide and prostaglandins. Circ Res 76:544-550

Kooijman M, Rongen GA, Smits P, Hopman MT (2003) Preserved alpha-adrenergic tone in the leg vascular bed of spinal cordinjured individuals. Circulation 108:2361-2367

Kooijman M, Thijssen DH, de Groot PC, Bleeker MW, van Kuppevelt HJ, Green DJ, Rongen GA, Smits P, Hopman MT (2008) Flow-mediated dilatation in the superficial femoral artery is nitric oxide mediated in humans. J Physiol 586:1137-1145

Kool MJ, Wijnen JA, Hoeks AP, Struyker-Boudier HA, Van Bortel LM (1991) Diurnal pattern of vessel-wall properties of large arteries in healthy men. J Hypertens Suppl 9:S108-S109

Kramsch DM, Aspen AJ, Abramowitz BM, Kreimendahl T, Hood WB Jr (1981) Reduction of coronary atherosclerosis by moderate conditioning exercise in monkeys on an atherogenic diet. N Engl J Med 305:1483-1489

Kroese AJ (1977) The effect of inactivity on reactive hyperaemia in the human calf: a study with strain gauge plethysmography. Scand J Clin Lab Invest 37:53-58

Krum H, Louis WJ, Brown DJ, Howes LG (1992) Pressor dose responses and baroreflex sensitivity in quadriplegic spinal cord injury patients. J Hypertens 10:245-250

LaMonte MJ, Blair SN, Church TS (2005) Physical activity and diabetes prevention. J Appl Physiol 99:1205-1213

Langille BL, O'Donnell F (1986) Reductions in arterial diameter produced by chronic decreases in blood flow are endotheliumdependent. Science 231:405-407

Langille BL, Bendeck MP, Keeley FW (1989) Adaptations of carotid arteries of young and mature rabbits to reduced carotid blood flow. Am J Physiol 256:H931-H939

Lash JM, Bohlen HG (1992) Functional adaptations of rat skeletal muscle arterioles to aerobic exercise training. J Appl Physiol 72:2052-2062

Laughlin MH (1995) Endothelium-mediated control of coronary vascular tone after chronic exercise training. Med Sci Sports Exerc 27:1135-1144

Laughlin MH, McAllister RM (1992) Exercise training-induced coronary vascular adaptation. J Appl Physiol 73:2209-2225

Laughlin MH, Ripperger J (1987) Vascular transport capacity of hindlimb muscles of exercise-trained rats. J Appl Physiol 62:438-443

Laughlin MH, Overholser KA, Bhatte MJ (1989) Exercise training increases coronary transport reserve in miniature swine. J Appl Physiol 67:1140-1149

Laughlin MH, Rubin LJ, Rush JW, Price EM, Schrage WG, Woodman CR (2003a) Short-term training enhances endothelium-dependent dilation of coronary arteries, not arterioles. J Appl Physiol 94:234-244

Laughlin MH, Turk JR, Schrage WG, Woodman CR, Price EM (2003b) Influence of coronary artery diameter on eNOS protein content. Am J Physiol Heart Circ Physiol 284:H1307-1312

Laughlin MH, Newcomer SC, Bender SB (2008) Importance of hemodynamic forces as signals for exercise-induced changes in endothelial cell phenotype. J Appl Physiol 104:588-600

Lavrencic A, Salobir BG, Keber I (2000) Physical training improves flow-mediated dilation in patients with the polymetabolic syndrome. Arterioscler Thromb Vasc Biol 20:551-555

Leon AS, Bloor CM (1968) Effects of exercise and its cessation on the heart and its blood supply. J Appl Physiol 24:485-490

Levy WC, Cerqueira MD, Harp GD, Johannessen KA, Abrass IB, Schwartz RS, Stratton JR (1998) Effect of endurance exercise training on heart rate variability at rest in healthy young and older men. Am J Cardiol 82:1236-1241

Lewis TV, Dart AM, Chin-Dusting JP, Kingwell BA (1999) Exercise training increases basal nitric oxide production from the forearm in hypercholesterolemic patients. Arterioscler Thromb Vasc Biol 19:2782-2787

Liang H, Chen D, Wang Y, Rimmer JH, Braunschweig CL (2007) Different risk factor patterns for metabolic syndrome in men with spinal cord injury compared with able-bodied men despite similar prevalence rates. Arch Phys Med Rehabil 88:1198-1204

Linke A, Schoene N, Gielen S, Hofer J, Erbs S, Schuler G, Hambrecht R (2001) Endothelial dysfunction in patients with chronic heart failure: systemic effects of lower-limb exercise training. J Am Coll Cardiol 37:392-397

Lloyd PG, Yang HT, Terjung RL (2001) Arteriogenesis and angiogenesis in rat ischemic hindlimb: role of nitric oxide. Am J Physiol Heart Circ Physiol 281:H2528-H2538

Logason K, Barlin T, Jonsson ML, Bostrom A, Hardemark HG, Karacagil S (2001) The importance of Doppler angle of insonation on differentiation between $50-69 \%$ and $70-99 \%$ carotid artery stenosis. Eur J Vasc Endovasc Surg 21:311-313

Louisy F, Schroiff P, Guell A (1997) Changes in leg vein filling and emptying characteristics and leg volumes during long-term headdown bed rest. J Appl Physiol 82:1726-1733

Maiorana A, O'Driscoll G, Cheetham C, Collis J, Goodman C, Rankin S, Taylor R, Green D (2000a) Combined aerobic and resistance exercise training improves functional capacity and strength in CHF. J Appl Physiol 88:1565-1570

Maiorana A, O'Driscoll G, Dembo L, Cheetham C, Goodman C, Taylor R, Green D (2000b) Effect of aerobic and resistance exercise training on vascular function in heart failure. Am $\mathrm{J}$ Physiol Heart Circ Physiol 279:H1999-2005

Maiorana A, O'Driscoll G, Cheetham C, Dembo L, Stanton K, Goodman C, Taylor R, Green D (2001a) The effect of combined aerobic and resistance exercise training on vascular function in type 2 diabetes. J Am Coll Cardiol 38:860-866

Maiorana A, O'Driscoll G, Dembo L, Goodman C, Taylor R, Green D (2001b) Exercise training, vascular function, and functional capacity in middle-aged subjects. Med Sci Sports Exerc 33:2022-2028

Maiorana A, O'Driscoll G, Goodman C, Taylor R, Green D (2002) Combined aerobic and resistance exercise improves glycemic control and fitness in type 2 diabetes. Diabetes Res Clin Pract $56: 115-123$

Maiorana A, O’Driscoll G, Taylor R, Green D (2003) Exercise and the nitric oxide vasodilator system. Sports Med 33:1013-1035

Mann GV, Shaffer RD, Anderson RS, Sandstead HH (1964) Cardiovascular Disease in the Masai. J Atheroscler Res 4:289312

Mann GV, Shaffer RD, Rich A (1965) Physical fitness and immunity to heart-disease in Masai. Lancet 2:1308-1310

Mann GV, Spoerry A, Gray M, Jarashow D (1972) Atherosclerosis in the Masai. Am J Epidemiol 95:26-37

Manson JE, Hu FB, Rich-Edwards JW, Colditz GA, Stampfer MJ, Willett WC, Speizer FE, Hennekens CH (1999) A prospective study of walking as compared with vigorous exercise in the prevention of coronary heart disease in women. $\mathrm{N}$ Engl $\mathrm{J}$ Med 341:650-658

Martin WH 3rd, Montgomery J, Snell PG, Corbett JR, Sokolov JJ, Buckey JC, Maloney DA, Blomqvist CG (1987) Cardiovascular adaptations to intense swim training in sedentary middle-aged men and women. Circulation 75:323-330

Martin WH 3rd, Kohrt WM, Malley MT, Korte E, Stoltz S (1990) Exercise training enhances leg vasodilatory capacity of 65-yr-old men and women. J Appl Physiol 69:1804-1809 
Maxwell LC, White TP, Faulkner JA (1980) Oxidative capacity, blood flow, and capillarity of skeletal muscles. J Appl Physiol 49:627-633

McAllister RM, Laughlin MH (1997) Short-term exercise training alters responses of porcine femoral and brachial arteries. J Appl Physiol 82:1438-1444

McAllister RM, Kimani JK, Webster JL, Parker JL, Laughlin MH (1996) Effects of exercise training on responses of peripheral and visceral arteries in swine. J Appl Physiol 80:216-225

McGowan CL, Levy AS, Millar PJ, Guzman JC, Morillo CA, McCartney N, Macdonald MJ (2006a) Acute vascular responses to isometric handgrip exercise and effects of training in persons medicated for hypertension. Am J Physiol Heart Circ Physiol 291:H1797-1802

McGowan CL, Visocchi A, Faulkner M, Verduyn R, Rakobowchuk M, Levy AS, McCartney N, Macdonald MJ (2006b) Isometric handgrip training improves local flow-mediated dilation in medicated hypertensives. Eur J Appl Physiol 98:355-362

McGowan CL, Levy AS, McCartney N, MacDonald MJ (2007a) Isometric handgrip training does not improve flow-mediated dilation in subjects with normal blood pressure. Clinical Science 112:403-409

McGowan CL, Visocchi A, Faulkner M, Verduyn R, Rakobowchuk M, Levy AS, McCartney N, MacDonald MJ (2007b) Isometric handgrip training improves local flow-mediated dilation in medicated hypertensives. Eur J Appl Physiol 99:227-234

Meyer AA, Kundt G, Lenschow U, Schuff-Werner P, Kienast W (2006) Improvement of early vascular changes and cardiovascular risk factors in obese children after a six-month exercise program. J Am Coll Cardiol 48:1865-1870

Miyachi M, Iemitsu M, Okutsu M, Onodera S (1998) Effects of endurance training on the size and blood flow of the arterial conductance vessels in humans. Acta Physiol Scand 163:13-16

Miyachi M, Tanaka H, Yamamoto K, Yoshioka A, Takahashi K, Onodera S (2001) Effects of one-legged endurance training on femoral arterial and venous size in healthy humans. J Appl Physiol 90:2439-2444

Mora S, Cook N, Buring JE, Ridker PM, Lee IM (2007) Physical activity and reduced risk of cardiovascular events: potential mediating mechanisms. Circulation 116:2110-2118

Moriguchi J, Itoh H, Harada S, Takeda K, Hatta T, Nakata T, Sasaki S (2005) Low frequency regular exercise improves flow-mediated dilatation of subjects with mild hypertension. Hypertens Res 28:315-321

Mullen MJ, Kharbanda RK, Cross J, Donald AE, Taylor M, Vallance P, Deanfield JE, MacAllister RJ (2001) Heterogenous nature of flow-mediated dilatation in human conduit arteries in vivo: relevance to endothelial dysfunction in hypercholesterolemia. Circ Res 88:145-151

Muller JM, Myers PR, Laughlin MH (1994) Vasodilator responses of coronary resistance arteries of exercise-trained pigs. Circulation 89:2308-2314

Myers J, Prakash M, Froelicher V, Do D, Partington S, Atwood JE (2002) Exercise capacity and mortality among men referred for exercise testing. N Engl J Med 346:793-801

Naylor LH, Weisbrod CJ, O'Driscoll G, Green DJ (2005) Measuring peripheral resistance and conduit arterial structure in humans using Doppler ultrasound. J Appl Physiol 98:23112315

Naylor LH, O'Driscoll G, Fitzsimons M, Arnolda LF, Green DJ (2006) Effects of training resumption on conduit arterial diameter in elite rowers. Med Sci Sports Exerc 38:86-92

Naylor LH, George K, O'Driscoll G, Green DJ (2008) The athlete's heart: a contemporary appraisal of the 'Morganroth hypothesis'. Sports Med 38:69-90
Nelson AJ, Juraska JM, Musch TI, Iwamoto GA (2005) Neuroplastic adaptations to exercise: neuronal remodeling in cardiorespiratory and locomotor areas. J Appl Physiol 99:2312-2322

Niebauer J, Cooke JP (1996) Cardiovascular effects of exercise: role of endothelial shear stress. J Am Coll Cardiol 28:1652-1660

O'Rourke MF (1999) Isolated systolic hypertension, pulse pressure, and arterial stiffness as risk factors for cardiovascular disease. Curr Hypertens Rep 1:204-211

Oldridge NB, Guyatt GH, Fischer ME, Rimm AA (1988) Cardiac rehabilitation after myocardial infarction. Combined experience of randomized clinical trials. Jama 260:945-950

Olive JL, Dudley GA, McCully KK (2003) Vascular remodeling after spinal cord injury. Med Sci Sports Exerc 35:901-907

Olson TP, Dengel DR, Leon AS, Schmitz KH (2006) Moderate resistance training and vascular health in overweight women. MSSE 38:1558-1564

Oltman CL, Parker JL, Adams HR, Laughlin MH (1992) Effects of exercise training on vasomotor reactivity of porcine coronary arteries. Am J Physiol 263:H372-382

Paffenbarger RS Jr, Hyde RT, Wing AL, Hsieh CC (1986) Physical activity, all-cause mortality, and longevity of college alumni. N Engl J Med 314:605-613

Pannier B, Slama M, Guerin A, Martel E, London G, Safar M, Cuche JL (1998) Further study on the carotid baroreflex system in the cardiovascular deconditioning induced by head-down tilt. Aviat Space Environ Med 69:904-910

Parnell MM, Holst DP, Kaye DM (2005) Augmentation of endothelial function following exercise training is associated with increased L-arginine transport in human heart failure. Clin Sci (Lond) 109:523-530

Patterson GC, Whelan RF (1955) Reactive hyperaemia in the human forearm. Clin Sci (Lond) 14:197-211

Paul JD, Powell TM, Thompson M, Benjamin M, Rodrigo M, Carlow A, Annavajjhala V, Shiva S, Dejam A, Gladwin MT, McCoy JP, Zalos G, Press B, Murphy M, Hill JM, Csako G, Waclawiw MA, Cannon RO 3rd (2007) Endothelial progenitor cell mobilization and increased intravascular nitric oxide in patients undergoing cardiac rehabilitation. J Cardiopulm Rehabil Prev 27:65-73

Pawelczyk JA, Zuckerman JH, Blomqvist CG, Levine BD (2001) Regulation of muscle sympathetic nerve activity after bed rest deconditioning. Am J Physiol Heart Circ Physiol 280:H2230 2239

Pelliccia A, Spataro A, Granata M, Biffi A, Caselli G, Alabiso A (1990) Coronary arteries in physiological hypertrophy: echocardiographic evidence of increased proximal size in elite athletes. Int J Sports Med 11:120-126

Philpott AC, Lonn E, Title LM, Verma S, Buithieu J, Charbonneau F, Anderson TJ (2009) Comparison of new measures of vascular function to flow mediated dilatation as a measure of cardiovascular risk factors. Am J Cardiol 103:1610-1615

Pohl U, Holtz J, Busse R, Bassenge E (1986) Crucial role of endothelium in the vasodilator response to increased flow in vivo. Hypertension 8:37-44

Powell KE, Blair SN (1994) The public health burdens of sedentary living habits: theoretical but realistic estimates. Med Sci Sports Exerc 26:851-856

Prior BM, Lloyd PG, Yang HT, Terjung RL (2003) Exercise-induced vascular remodeling. Exerc Sport Sci Rev 31:26-33

Pullin CH, Bellamy MF, Bailey D, Ashton M, Davies B, Williams S, Goodfellow J, Wilson JF, Lewis MJ (2004) Time course of changes in endothelial function following exercise in habitually sedentary men. J Exerc Physiol Online 7:12-22

Pyke KE, Tschakovsky ME (2007) Peak vs. total reactive hyperemia: which determines the magnitude of flow-mediated dilation? J Appl Physiol 102:1510-1519 
Quyyumi AA, Dakak N, Andrews NP, Husain S, Arora S, Gilligan DM, Panza JA, Cannon RO 3rd (1995) Nitric oxide activity in the human coronary circulation. Impact of risk factors for coronary atherosclerosis. J Clin Invest 95:1747-1755

Radegran G (1997) Ultrasound Doppler estimates of femoral artery blood flow during dynamic knee extensor exercise in humans. J Appl Physiol 83:1383-1388

Radegran G, Saltin B (1998) Muscle blood flow at onset of dynamic exercise in humans. Am J Physiol 274:H314-322

Radegran G, Saltin B (1999) Nitric oxide in the regulation of vasomotor tone in human skeletal muscle. Am J Physiol 276:H1951-1960

Rakobowchuk M, McGowan CL, de Groot PC, Hartman JW, Phillips SM, MacDonald MJ (2005) Endothelial function of young healthy males following whole body resistance training. J Appl Physiol 98:2185-2190

Rakobowchuk M, Tanguay S, Burgomaster KA, Howarth KR, Gibala MJ, MacDonald MJ (2008) Sprint interval and traditional endurance training induce similar improvements in peripheral arterial stiffness and flow-mediated dilation in healthy humans. Am J Physiol Regul Integr Comp Physiol 295:R236-R242

Ray CA, Hume KM (1998) Sympathetic neural adaptations to exercise training in humans: insights from microneurography. Med Sci Sports Exerc 30:387-391

Rennie KL, Hemingway H, Kumari M, Brunner E, Malik M, Marmot M (2003) Effects of moderate and vigorous physical activity on heart rate variability in a British study of civil servants. Am J Epidemiol 158:135-143

Rodbard S, Sarzana D (1975) Tolerance to unilateral or bilateral ischemic hand exercise. J Appl Physiol 38:817-818

Rose G, Prineas RJ, Mitchell JR (1967) Myocardial infarction and the intrinsic calibre of coronary arteries. Br Heart J 29:548-552

Rowell LB (1993) Human cardiovascular control. Oxford University Press, New York

Rowell LB, O'Leary DS, Kellogg DL (1996) Integration of cardiovascular control systems in dynamic exercise. In: Rowell LB, Shepherd JT (eds) Handbook of physiology. Oxford University Press, Oxford

Rubanyi GM, Romero JC, Vanhoutte PM (1986) Flow-induced release of endothelium-derived relaxing factor. Am J Physiol 250:H1145-H1149

Rudic RD, Shesely EG, Maeda N, Smithies O, Segal SS, Sessa WC (1998) Direct evidence for the importance of endotheliumderived nitric oxide in vascular remodeling. J Clin Invest 101:731-736

Saltin B, Nazar K, Costill DL, Stein E, Jansson E, Essen B, Gollnick $\mathrm{D}$ (1976) The nature of the training response; peripheral and central adaptations of one-legged exercise. Acta Physiol Scand 96:289-305

Schjerve IE, Tyldum GA, Tjonna AE, Stolen TO, Loennechen JP, Hansen HE, Haram PM, Heinrich G, Bye A, Najjar SM, Smith GL, Slordahl SA, Kemi OJ, Wisloff U (2008) Both aerobic endurance and strength training programs improve cardiovascular health in obese adults. Clin Sci (Lond) 75(4 Suppl):53S-58S

Schmidt A, Pleiner J, Bayerle-Eder M, Wiesinger GF, Rodler S, Quittan M, Mayer G, Wolzt M (2002) Regular physical exercise improves endothelial function in heart transplant recipients. Clin Transplant 16:137-143

Schmidt-Trucksass A, Schmid A, Brunner C, Scherer N, Zach G, Keul J, Huonker M (2000) Arterial properties of the carotid and femoral artery in endurance- trained and paraplegic subjects. J Appl Physiol 89:1956-1963

Sciacqua A, Candigliota M, Ceravolo R, Scozzafava A, Sinopoli F, Corsonello A, Sesti G, Perticone F (2003) Weight loss in combination with physical activity improves endothelial dysfunction in human obesity. Diabetes Care 26:1673-1678

Sessa WC, Pritchard K, Seyedi N, Wang J, Hintze TH (1994) Chronic exercise in dogs increases coronary vascular nitric oxide production and endothelial cell nitric oxide synthase gene expression. Circ Res 74:349-353

Sesso HD, Paffenbarger RS Jr, Lee IM (2000) Physical activity and coronary heart disease in men: the Harvard Alumni Health Study. Circulation 102:975-980

Shephard RJ, Balady GJ (1999) Exercise as cardiovascular therapy. Circulation 99:963-972

Shepherd JT (1983) Circulation to skeletal muscle. Handbook of physiology. The cardiovascular system peripheral circulation and organ blood flow. Am Physiol Soc, Bethesda, pp 319-370

Shoemaker JK, Hogeman CS, Silber DH, Gray K, Herr M, Sinoway LI (1998) Head-down-tilt bed rest alters forearm vasodilator and vasoconstrictor responses. J Appl Physiol 84:1756-1762

Silber DH, Sinoway LI (1990) Reversible impairment of forearm vasodilation after forearm casting. J Appl Physiol 68:19451949

Silber D, McLaughlin D, Sinoway L (1991) Leg exercise conditioning increases peak forearm blood flow. J Appl Physiol 71:1568-1573

Simon A, Gariepy J, Chironi G, Megnien JL, Levenson J (2002) Intima-media thickness: a new tool for diagnosis and treatment of cardiovascular risk. J Hypertens 20:159-169

Sinoway LI, Musch TI, Minotti JR, Zelis R (1986) Enhanced maximal metabolic vasodilatation in the dominant forearms of tennis players. J Appl Physiol 61:673-678

Sinoway LI, Shenberger J, Wilson J, McLaughlin D, Musch T, Zelis R (1987) A 30-day forearm work protocol increases maximal forearm blood flow. J Appl Physiol 62:1063-1067

Sivertsson R (1970) The hemodynamic importance of structural vascular changes in essential hypertension. Acta Physiol Scand Suppl 343:1-56

Snell PG, Martin WH, Buckey JC, Blomqvist CG (1987) Maximal vascular leg conductance in trained and untrained men. J Appl Physiol 62:606-610

Sonka M, Liang W, Kanani P, Allan J, DeJong S, Kerber R, McKay C (1998) Intracardiac echocardiography: computerized detection of left ventricular borders. Int J Card Imaging 14:397-411

Stoner L, Sabatier M, VanhHiel L, Groves D, Ripley D, Palardy G, McCully K (2006) Upper vs lower extremity arterial function after spinal cord injury. J Spinal Cord Med 29:138-146

Sugawara J, Hayashi K, Kaneko F, Yamada H, Kizuka T, Tanaka H (2004) Reductions in basal limb blood flow and lumen diameter after short-term leg casting. Med Sci Sports Exerc 36:1689-1694

Sugawara J, Komine H, Hayashi K, Yoshizawa M, Otsuki T, Shimojo N, Miyauchi T, Yokoi T, Maeda S, Tanaka H (2007) Systemic alpha-adrenergic and nitric oxide inhibition on basal limb blood flow: effects of endurance training in middle-aged and older adults. Am J Physiol Heart Circ Physiol 293:H1466-1472

Sun D, Huang A, Koller A, Kaley G (1994) Short-term daily exercise activity enhances endothelial NO synthesis in skeletal muscle arterioles of rats. J Appl Physiol 76:2241-2247

Sun D, Huang A, Koller A, Kaley G (1998) Adaptation of flowinduced dilation of arterioles to daily exercise. Microvasc Res 56:54-61

Takase B, Uehata A, Akima T, Nagai T, Nishioka T, Hamabe A, Satomura K, Ohsuzu F, Kurita A (1998) Endothelium-dependent flow-mediated vasodilation in coronary and brachial arteries in suspected coronary artery disease. Am J Cardiol 82:1535-1539

Takase B, Hamabe A, Satomura K, Uehata A, Ohsuzu F, Ishihara M, Kurita A (2005) Close relationship between the vasodilator response to acetylcholine in the brachial and coronary artery in suspected coronary artery disease. Int J Cardiol 105:58-66 
Takeshita A, Mark AL (1980) Decreased vasodilator capacity of forearm resistance vessels in borderline hypertension. Hypertension 2:610-616

Tanaka H, Swenson T (1998) Impact of resistance training on endurance performance. Sports Med 25:191-200

Tanaka H, Seals DR, Monahan KD, Clevenger CM, DeSouza CA, Dinenno FA (2002) Regular aerobic exercise and the age-related increase in carotid artery intima-media thickness in healthy men. J Appl Physiol 92:1458-1464

Tanasescu M, Leitzmann MF, Rimm EB, Willett WC, Stampfer MJ, $\mathrm{Hu}$ FB (2002) Exercise type and intensity in relation to coronary heart disease in men. Jama 288:1994-2000

Taylor RS, Brown A, Ebrahim S, Jolliffe J, Noorani H, Rees K, Skidmore B, Stone JA, Thompson DR, Oldridge N (2004) Exercise-based rehabilitation for patients with coronary heart disease: systematic review and meta-analysis of randomized controlled trials. Am J Med 116:682-692

The Long-Term Intervention with Pravastatin in Ischaemic Disease (LIPID) Study Group (1998) Prevention of cardiovascular events and death with pravastatin in patients with coronary heart disease and a broad range of initial cholesterol levels. N Engl J Med 339:1349-1357

Thijssen DHJ, Hopman MTE (2008) Exercise training does not induce vascular adaptations beyond the active muscle beds. J Appl Physiol 105:1004-1006

Thijssen DH, Heesterbeek P, van Kuppevelt DJ, Duysens J, Hopman MT (2005) Local vascular adaptations after hybrid training in spinal cord-injured subjects. Med Sci Sports Exerc 37:11121118

Thijssen DH, de Groot P, Kooijman M, Smits P, Hopman MT (2006) Sympathetic nervous system contributes to the age-related impairment of flow-mediated dilation of the superficial femoral artery. Am J Physiol 291:H3122-3129

Thijssen DH, de Groot PC, Smits P, Hopman MT (2007a) Vascular adaptations to 8-week cycling training in older men. Acta Physiol (Oxf) 190(3):221-228

Thijssen DH, Ellenkamp R, Kooijman M, Pickkers P, Rongen GA, Hopman MT, Smits P (2007b) A causal role for endothelin-1 in the vascular adaptation to skeletal muscle deconditioning in spinal cord injury. Arterioscler Thromb Vasc Biol 27:325-331

Thijssen DHJ, Rongen GA, van Dijk A, Smits P, Hopman MTE (2007c) Enhanced endothelin-1-mediated leg vascular tone in healthy older subjects. J Appl Physiol 103:852-857

Thijssen DH, Kooijman M, de Groot PC, Bleeker MW, Smits P, Green DJ, Hopman MT (2008a) Endothelium-dependent and -independent vasodilation of the superficial femoral artery in spinal cord-injured subjects. J Appl Physiol 104:1387-1393

Thijssen DH, Rongen GA, Smits P, Hopman MT (2008b) Physical (in)activity and endothelium-derived constricting factors: overlooked adaptations. J Physiol 586:319-324

Thijssen DH, Dawson EA, Black MA, Hopman MT, Cable NT, Green DJ (2009) Brachial artery blood flow responses to different modalities of lower limb exercise. Med Sci Sports Exerc 41:1072-1079

Thompson PD (2004) D. Bruce Dill Historical lecture. Historical concepts of the athlete's heart. Med Sci Sports Exerc 36:363370

Thompson PD, Buchner D, Pina IL, Balady GJ, Williams MA, Marcus BH, Berra K, Blair SN, Costa F, Franklin B, Fletcher GF, Gordon NF, Pate RR, Rodriguez BL, Yancey AK, Wenger NK (2003) Exercise and physical activity in the prevention and treatment of atherosclerotic cardiovascular disease: a statement from the Council on Clinical Cardiology (Subcommittee on Exercise, Rehabilitation, and Prevention) and the Council on Nutrition, Physical Activity, and Metabolism (Subcommittee on Physical Activity). Circulation 107:3109-3116
Tinken TM, Thijssen DHJ, Black MA, Cable NT, Green DJ (2008) Conduit artery functional adaptation is reversible and precedes structural changes to exercise training in humans. J Physiol (Lond) 586:5003-5012

Tinken TM, Thijssen DHJ, Hopkins ND, Dawson EA, Cable NT, Green DJ (2009) Shear stress mediated endothelial adaptations to exercise training in humans. Hypertension (in press)

Tousoulis D, Tentolouris C, Crake T, Toutouzas P, Davies G (1997) Basal and flow-mediated nitric oxide production by atheromatous coronary arteries. J Am Coll Cardiol 29:1256-1262

Tronc F, Wassef M, Esposito B, Henrion D, Glagov S, Tedgui A (1996) Role of NO in flow-induced remodeling of the rabbit common carotid artery. Arterioscler Thromb Vasc Biol 16:12561262

Tsuji H, Venditti FJ, Manders ES, Evans JC, Larson MG, Feldman CL, Levy D (1994) Reduced heart rate variability and mortality risk in an elderly cohort. The Framingham Heart Study. Circulation 90:878-883

Turnbull F (2003) Effects of different blood-pressure-lowering regimens on major cardiovascular events: results of prospectivelydesigned overviews of randomised trials. Lancet 362:1527-1535

Tuttle JL, Nachreiner RD, Bhuller AS, Condict KW, Connors BA, Herring BP, Dalsing MC, Unthank JL (2001) Shear level influences resistance artery remodeling: wall dimensions, cell density, and eNOS expression. Am J Physiol Heart Circ Physiol 281:H1380-1389

USDHHS (1996) Physical activity and health: a report of the surgeon general. In: Department of Health and Human Services, National Center for Chronic Disease Prevention and Health promotion. (ed). Atlanta, GA, US

Van Guilder GP, Westby CM, Greiner JJ, Stauffer BL, DeSouza CA (2007) Endothelin-1 vasoconstrictor tone increases with age in healthy men but can be reduced by regular aerobic exercise. Hypertension 50:403-409

Vita JA, Holbrook M, Palmisano J, Shenouda SM, Chung WB, Hamburg NM, Eskenazi BR, Joseph L, Shapira OM (2008) Flow-induced arterial remodeling relates to endothelial function in the human forearm. Circulation 117:3126-3133

Vona M, Rossi A, Capodaglio P, Rizzo S, Servi P, Marchi MD, Cobelli F (2004) Impact of physical training and detraining on endothelium-dependent vasodilation in patients with recent acute myocardial infarction. Am Heart J 147:1039-1046

Vona M, Codeluppi GM, Iannino T, Ferrari E, Bogousslavsky J, von Segesser LK (2009) Effects of different types of exercise training followed by detraining on endothelium-dependent dilation in patients with recent myocardial infarction. Circulation 119:1601-1608

Walsh JH, Bilsborough W, Maiorana A, Best M, O'Driscoll GJ, Taylor RR, Green DJ (2003a) Exercise training improves conduit vessel function in patients with coronary artery disease. J Appl Physiol 95:20-25

Walsh JH, Yong G, Cheetham C, Watts GF, O’Driscoll GJ, Taylor RR, Green DJ (2003b) Effects of exercise training on conduit and resistance vessel function in treated and untreated hypercholesterolaemic subjects. Eur Heart J 24:1681-1689

Wamhoff BR, Bowles DK, Dietz NJ, Hu Q, Sturek M (2002) Exercise training attenuates coronary smooth muscle phenotypic modulation and nuclear $\mathrm{Ca} 2+$ signaling. Am J Physiol Heart Circ Physiol 283:H2397-H2410

Wang J, Wolin MS, Hintze TH (1993) Chronic exercise enhances endothelium-mediated dilation of epicardial coronary artery in conscious dogs. Circ Res 73:829-838

Watenpaugh DE, Buckey JC, Lane LD, Gaffney FA, Levine BD, Moore WE, Wright SJ, Blomqvist CG (2001) Effects of spaceflight on human calf hemodynamics. J Appl Physiol 90:1552-1558 
Watts K, Beye P, Siafarikas A, Davis EA, Jones TW, O’Driscoll G, Green DJ (2004a) Exercise training normalizes vascular dysfunction and improves central adiposity in obese adolescents. J Am Coll Cardiol 43:1823-1827

Watts K, Beye P, Siafarikas A, O'Driscoll G, Jones TW, Davis EA, Green DJ (2004b) Effects of exercise training on vascular function in obese children. J Pediatr 144:620-625

Wei M, Kampert JB, Barlow CE, Nichaman MZ, Gibbons LW, Paffenbarger RS Jr, Blair SN (1999) Relationship between low cardiorespiratory fitness and mortality in normal-weight, overweight, and obese men. JAMA 282:1547-1553

Westhoff TH, Franke N, Schmidt S, Vallbracht-Israng K, Meissner R, Yildirim H, Schlattmann P, Zidek W, Dimeo F, van der Giet M (2007) Too old to benefit from sports? The cardiovascular effects of exercise training in elderly subjects treated for isolated systolic hypertension. Kidney Blood Press Res 30:240-247

Whitney RJ (1953) The measurement of volume changes in human limbs. J Physiol 121:1-27

Wichterle D, Simek J, La Rovere MT, Schwartz PJ, Camm AJ, Malik M (2004) Prevalent low-frequency oscillation of heart rate: novel predictor of mortality after myocardial infarction. Circulation 110:1183-1190

Wijnen JA, Kuipers H, Kool MJ, Hoeks AP, van Baak MA, Struyker Boudier HA, Verstappen FT, Van Bortel LM (1991) Vessel wall properties of large arteries in trained and sedentary subjects. Basic Res Cardiol 86(Suppl 1):25-29

Wilt TJ, Bloomfield HE, MacDonald R, Nelson D, Rutks I, Ho M, Larsen G, McCall A, Pineros S, Sales A (2004) Effectiveness of statin therapy in adults with coronary heart disease. Arch Intern Med 164:1427-1436

Wisloff U, Stoylen A, Loennechen JP, Bruvold M, Rognmo O, Haram PM, Tjonna AE, Helgerud J, Slordahl SA, Lee SJ, Videm V, Bye A, Smith GL, Najjar SM, Ellingsen O, Skjaerpe T (2007) Superior cardiovascular effect of aerobic interval training versus moderate continuous training in heart failure patients: a randomized study. Circulation 115:3086-3094
Woo KS, Chook P, Yu CW, Sung RY, Qiao M, Leung SS, Lam CW, Metreweli C, Celermajer DS (2004) Effects of diet and exercise on obesity-related vascular dysfunction in children. Circulation 109:1981-1986

Woodman CR, Muller JM, Laughlin MH, Price EM (1997) Induction of nitric oxide synthase mRNA in coronary resistance arteries isolated from exercise-trained pigs. Am J Physiol 273:H25752579

Wray DW, Uberoi A, Lawrenson L, Richardson RS (2006) Evidence of preserved endothelial function and vascular plasticity with age. Am J Physiol 290:H1271-H1277

Wyatt HL, Mitchell J (1978) Influences of physical conditioning and deconditioning on coronary vasculature of dogs. J Appl Physiol 45:619-625

Xiang GD, Wang YL (2004) Regular aerobic exercise training improves endothelium-dependent arterial dilation in patients with impaired fasting glucose. Diabetes Care 27:801-802

Yasuda Y, Miyamura M (1983) Cross transfer effects of muscular training on blood flow in the ipsilateral and contralateral forearms. Eur J Appl Physiol Occup Physiol 51:321-329

Zamir M (1977) Shear forces and blood vessel radii in the cardiovascular system. J Gen Physiol 69:449-461

Zarins CK, Zatina MA, Giddens DP, Ku DN, Glagov S (1987) Shear stress regulation of artery lumen diameter in experimental atherogenesis. J Vasc Surg 5:413-420

Zelis R, Mason DT, Braunwald E (1968) A comparison of the effects of vasodilator stimuli on peripheral resistance vessels in normal subjects and in patients with congestive heart failure. J Clin Invest 47:960-970

Zeppilli P, Vannicelli R, Santini C, Dello Russo A, Picani C, Palmieri V, Cameli S, Corsetti R, Pietrangeli L (1995) Echocardiographic size of conductance vessels in athletes and sedentary people. Int J Sports Med 16:38-44

Zhang LF (2001) Vascular adaptation to microgravity: what have we learned? J Appl Physiol 91:2415-2430 